\title{
wane \\ Detailed Analysis of Exergy Destruction of All Basic Types of Heat Exchangers
}

\author{
Martina Rauch * (D), Saša Mudrinić and Antun Galović
}

Citation: Rauch, M.; Mudrinić, S.; Galović, A. Detailed Analysis of Exergy Destruction of All Basic Types of Heat Exchangers. Processes 2022, 10, 249. https://doi.org/10.3390/ pr10020249

Academic Editor: Ireneusz Zbicinski

Received: 30 November 2021

Accepted: 24 January 2022

Published: 27 January 2022

Publisher's Note: MDPI stays neutral with regard to jurisdictional claims in published maps and institutional affiliations.

Copyright: (C) 2022 by the authors. Licensee MDPI, Basel, Switzerland. This article is an open access article distributed under the terms and conditions of the Creative Commons Attribution (CC BY) license (https:// creativecommons.org/licenses/by/ $4.0 /)$.
Faculty of Mechanical Engineering and Naval Architecture, University of Zagreb, Ivana Lučića 5, HR-10000 Zagreb, Croatia; sasa.mudrinic@fsb.hr (S.M.); antun.galovic@fsb.hr (A.G.)

* Correspondence: martina.rauch@fsb.hr; Tel.: +385-1-6168-161

Abstract: Dimensionless expressions of exergy destruction, normalized to ambient temperature and heat capacity of the weaker stream, for all basic types of recuperators are derived. The analytical expressions for maximum exergy destruction were calculated using the GNU Octave software for all recuperators, namely parallel-flow and counter-flow recuperators, and all forms of cross-flow heat exchangers, namely without mixing of streams, only mixing the streamlines of the weaker stream, only mixing the streamlines of the stronger stream and mixing the weaker and stronger streams. For parallel-flow and counter-flow recuperators, as well as for their special cases, expressions for local and total exergy destruction are given. It is shown that the maximum exergy destruction, as a local extreme, is the same for all recuperators for mutually equal values of the quantities $\pi_{3}$ (ratio of the heat capacity of the weaker stream to the heat capacity of the stronger stream) and $\pi_{T}$ (ratio of the inlet temperature of the stronger stream to the inlet temperature of the weaker stream). The ratio of exergy destruction to effectiveness of each basic type of recuperator is further analyzed. The obtained results are presented and interpreted in appropriate dimensionless diagrams.

Keywords: recuperators; local and total exergy destruction; dimensionless analytical solution

\section{Introduction}

Back in 1938, Professor Bošnjaković wrote the pioneering paper "Kampf den Nichtumkehrbarkeiten" [1], which states the fact that in all thermal problems it is necessary to detect causes of irreversibility and to reduce them if possible. Shortly afterward, Professor Rant introduces the notion of exergy which is also directly related to irreversibilities in the observed process [2]. Each process, according to the second law of thermodynamics, generates a positive increase in entropy which when multiplied by the thermodynamic ambient temperature, according to the Gouy-Stodola theorem [3,4], denotes exergy destruction. Many scientific books, as well as many scientific papers, have been written in which numerous thermal problems are analyzed from the aspect of entropy or exergy. The concepts of irreversibility, entropy generation and exergy destruction are well known and were described decades ago by Bejan [5].

To evaluate the performance of heat exchange, some researchers presented reviews of second-law-based analysis [6,7] with classified performance criteria (entropy and exergy as evaluation parameters). Estimation of thermodynamic efficiency is based on an assessment of energy that is available to be used (exergy), or analogously irreversibility (entropy) generation. It can be seen from literature review how entropy generation minimization and exergy destruction are powerful tools in the optimization of thermodynamic systems. Many researchers have investigated this important topic, using experimental or numerical methods in different types of heat exchangers and different fluids inside them. Heat transfer and entropy generation are numerically investigated in shell and helically coiled finned tube heat exchangers and presented in the study of Sepehr et al. [8]. According to the results, correlation is suggested for the calculation of entropy generation rate based 
on the values of the operational and geometrical variables. Genić et al. [9] developed a methodology of entropy generation minimization for counter-current and cocurrent heat exchangers which can be applied in the general case for all types of heat exchangers. The methodology is based on combining the second law of thermodynamics with the number of transfer units (NTU) method. In order to investigate the entropy transportation process inside a plate and tube heat exchanger, Guzmán et al. [10] conducted numerical simulations in their work. The authors analyzed and compared entropy levels around tubes with circular and elliptical cross-sections. The purpose of the comparison was to determine how the entropy flux contributes to the value of the entropy in certain regions of the flow field. An experimental study was conducted by Goh et al. [11] with the aim to determine the effects of interturbulator distance of rotating turbulator inserts on the heat transfer enhancement and entropy generation of forced convection in the turbulent flow region of a heat exchanger. Etghani and Baboli [12] developed a numerical model of a shell and helical tube heat exchanger and examined the effect of geometry and design parameters on heat transfer and exergy loss. The Taguchi method was used to obtain the optimum values of the design variables. According to the research, it has been proven that tube diameter and cold flow rate are the most significant design parameters of heat transfer and exergy loss. In their study, Wang et al. [13] established a numerical method for analyzing the effect of fin geometry and the inlet mass flow rate on the exergy loss in cylindrical shell and the helically coiled finned tube heat exchangers with an internal core inside the shell. The study showed that exergy loss increases with the increase in the inlet mass flow rate of the shell side, height and number of fins, NTU, heat transfer and operation of the fan. Alimoradi [14] in his study presents exergy analysis for forced convection heat transfer in shell and helically coiled tube heat exchangers. The effect of operational and geometrical parameters on the exergy efficiency was obtained. Results of the study show that efficiency decreases linearly with the increase in the fluid's dimensionless inlet temperature difference. Al-Salem et al. [15] used a numerical method to obtain correlations for estimation of the annulus section exergy efficiency and coefficient of exergy performance for steady-state heat transfer and fluid flow in the annulus section of a tube-in-tube conically coiled heat exchanger. The study showed that the highest values of the turn number and the minimum values of the Reynolds number, Prandtl number, tube diameter ratio and the cone angle in the studied range maximize the exergy efficiency and coefficient of exergy performance. Wilhelmsen et al. [16] evaluated the strategies to reduce exergy destruction and entropy production in the plate-fin heat exchangers in the cryogenic part of a hydrogen liquefaction facility. Two main sources of exergy loss are thermal gradients and ortho-para hydrogen conversion. The proposed solution for reducing exergy destruction is a combination of an improved catalyst and the use of hydrogen and helium-neon as refrigerants. Abu-Hamdeh et al. [17] used a numerical method to simulate the three-dimensional turbulent thermal energy transfer and fluid flow through a finned tube heat exchanger. Energy and exergy analyses were performed and a multiobjective model was defined to obtain the optimal and critical values of the operational and geometrical parameters. Equations for estimation of thermal effectiveness, dimensionless exergy loss and dimensionless work were suggested. The heat exchanger for air dehumidification using liquid desiccant is mainly composed of an air-solution heat exchanger (dehumidifier) and a solution-refrigerant heat exchanger, wherein there are three fluids, i.e., air, desiccant solution, and refrigerant. It was found that the largest exergy destructions took place in the regenerator and dehumidifier. Findings of research of Guan et al. [18] can be used for achieving an efficient air dehumidification process in a heat exchanger using liquid desiccant. Recent work from Xie et al. [19] fills the gap of heat transfer and the geometrical optimization study of helical microfin tubes. Based on the exergy destruction minimization principle, the geometrical parameters are optimized by using numerical methods.

Many researchers have examined the attributes of conventional fluids inside heat exchangers. The ordinary working fluids possess great thermal resistance owing to their poor thermal conductivity and therefore can negatively influence the overall efficiency of 
heat exchangers. To address this shortcoming, nanofluids (which comprise the suspension of nanoscaled metallic or nonmetallic particles inside a pure liquid) are used as advanced heat transfer fluids $[20,21]$, but also many second-law-based analyses have been performed with them [22,23].

The idea behind this paper is to develop a dimensionless mathematical model for the calculation of exergy destruction for all basic types of heat exchangers using dimensionless quantities commonly used in effectiveness-NTU energy calculations. This means that in the scope of this paper, the influence of these quantities on exergy destruction in heat exchangers, which is a consequence only of heat transfer at final temperature differences between the streams, is analyzed in detail. However, total exergy destruction of a heat exchanger is a summarized consequence of the local contributions, so within this paper, a local and then global approach is used to obtain the solution of exergy destruction. The analytical expressions for maximum exergy destruction were calculated using the GNU Octave software (Version 3.4.3, John W. Eaton, Madison, WI, USA). The basic types of heat exchangers discussed in this paper are those for which every stream, weaker and stronger, passes over the heat exchanging area only once. Division is based on mutual stream direction: parallel-flow heat exchanger, counter-flow heat exchanger, cross-flow heat exchanger without mixing of streamlines, cross-flow heat exchanger with mixing of only weaker stream streamlines, cross-flow heat exchanger with mixing of only stronger stream streamlines and cross-flow heat exchanger with mixing of weaker and stronger stream streamlines.

\section{Mathematical Model}

Model development for calculation of dimensionless exergy destruction uses the same presumptions as in development of existing models for function dependence $\varepsilon=\pi_{1}=\mathrm{f}\left(\pi_{2}=\mathrm{NTU}\right.$; $\pi_{3}$ ) [24], which means a constant value of the heat transfer coefficient and heat capacity of weaker and stronger streams. For calculating the mentioned values, the physical properties of streams are taken as arithmetic means of the inlet and outlet temperatures of each stream. The model neglects the effect of the environment on the amount of heat flow rate, which means that the heat exchanger is observed as an adiabatic system. The model for the calculation of the ratio of exergy destruction to effectiveness is obtained using the same presumptions, so those results are also connected to the operating point of the heat exchanger.

In this work, exergy destruction is a result of irreversible heat transfer between streams. Besides heat transfer, the exergy destruction in general depends also on stream pressure drop in a heat exchanger. However, as the primary goal of this paper is to connect the operating point of the heat exchanger given by the function $\varepsilon=\pi_{1}=\mathrm{f}\left(\pi_{2}=N T U ; \pi_{3}\right)$ with the corresponding dimensionless exergy destruction as well as the ratio of exergy destruction to effectiveness of each basic type of recuperator, the impact of the stream pressure drop is neglected.

\subsection{Local and Total Exergy Destruction of Parallel-Flow and Counter-Flow Recuperators}

Since the total exergy destruction on the finite-surface recuperator is a consequence of the summarized local effects, the differential amount of exergy destruction for the observed recuperators is shown in Figure 1a,b.

The differential amount of heat transfer rate is [24]

$$
\mathrm{d} \Phi=U\left(T_{1}-T_{2}\right) \mathrm{d} A
$$

The corresponding differential entropy increment is given with the following equation [5]:

$$
\mathrm{d} S_{\text {is.syst }}=-\frac{\mathrm{d} \Phi}{T_{1}}+\frac{\mathrm{d} \Phi}{T_{2}}=U \frac{\left(T_{1}-T_{2}\right)^{2}}{T_{1} T_{2}} \mathrm{~d} A
$$




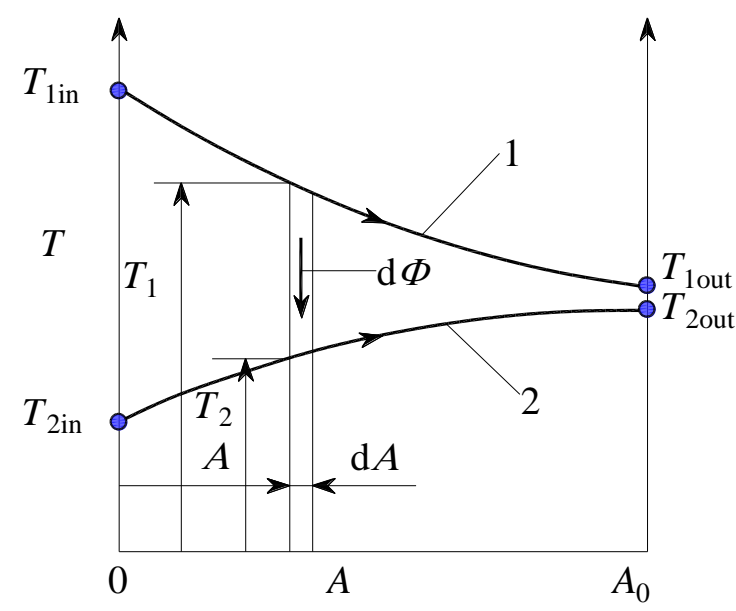

(a)

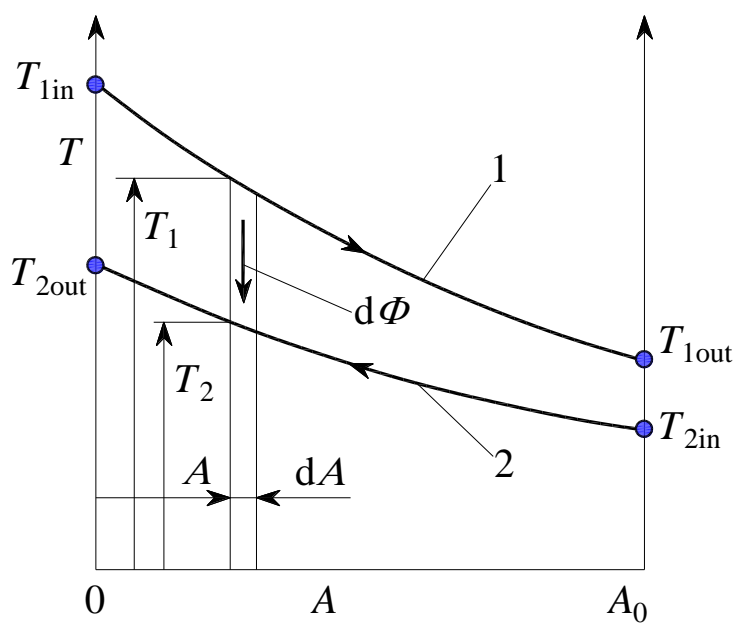

(b)

Figure 1. The derivation of local exergy destruction in (a) parallel-flow and (b) counter-flow heat exchangers.

The total entropy generated due to irreversible heat transfer is

$$
\Delta S_{\text {is.syst }}=U \int_{A=0}^{A} \frac{\left(T_{1}-T_{2}\right)^{2}}{T_{1} T_{2}} \mathrm{~d} A
$$

The following dimensionless quantities are also used for further analysis [24,25]:

$$
\begin{gathered}
\pi_{3}=\frac{\dot{m}_{1} c_{p 1}}{\dot{m}_{2} c_{p 2}}=\frac{\dot{C}_{1}}{\dot{C}_{2}} \\
\pi_{T}=\frac{T_{2 \text { in }}}{T_{1 \text { in }}} \\
\pi_{2}=N T U=U A_{0} / \dot{C}_{1} \\
\pi_{1}=\varepsilon=\frac{T_{1 \text { in }}-T_{1 \text { out }}}{T_{1 \text { in }}-T_{2 \text { in }}}
\end{gathered}
$$

\subsubsection{Parallel-Flow Recuperator}

By placing a system of energy differential equations on a parallel-flow recuperator, the following expressions for local values of temperatures of weaker and stronger streams are determined [25]:

$$
\begin{gathered}
T_{1}=B_{1}+B_{2} \exp \left(-\left(1+\pi_{3}\right) \frac{A}{A_{0}}\right) \\
T_{2}=B_{1}-\pi_{3} B_{2} \exp \left(-\left(1+\pi_{3}\right) \frac{A}{A_{0}}\right)
\end{gathered}
$$

where the constants are determined from the boundary condition that for $A=0, T_{1}=T_{1 \text { in }}$ and $T_{2}=T_{2 o u t}$.

$$
B_{1}=\frac{T_{2 \text { in }}+\pi_{3} T_{1 \text { in }}}{1+\pi_{3}}, B_{2}=\frac{T_{1 \text { in }}-T_{2 \text { in }}}{1+\pi_{3}}
$$

By including Equations (8) and (9) together with Equation (10) in Equation (3), and using the Gouy-Stodola theorem [3,4], and after integration, the following expression for local exergy destruction in a parallel recuperator is obtained: 


$$
\begin{gathered}
\left(\frac{\Delta E x\left(A / A_{0}\right)}{C_{1} T_{\mathrm{ok}}}\right)_{p a r}=\ln \frac{\pi_{T}+\pi_{3}+\left(1-\pi_{T}\right) \exp \left(-\pi_{2}\left(1+\pi_{3}\right) \frac{A}{A_{0}}\right)}{1+\pi_{3}}+ \\
\frac{1}{\pi_{3}} \ln \frac{\pi_{T}+\pi_{3}-\pi_{3}\left(1-\pi_{T}\right) \exp \left(-\pi_{2}\left(1+\pi_{3}\right) \frac{A}{A_{0}}\right)}{\left(1+\pi_{3}\right) \pi_{T}}
\end{gathered}
$$

where $T_{\mathrm{ok}}$ is ambient temperature.

If $A / A_{0}=1.0$ is included in the above equation, an expression that describes the total (global) exergy destruction of the parallel-flow recuperator is obtained:

$$
\begin{aligned}
& \left(\frac{\Delta E x}{C_{1} T_{\mathrm{ok}}}\right)_{p a r}=\ln \frac{\pi_{T}+\pi_{3}+\left(1-\pi_{T}\right) \exp \left(-\pi_{2}\left(1+\pi_{3}\right)\right)}{1+\pi_{3}}+ \\
& \frac{1}{\pi_{3}} \ln \frac{\pi_{T}+\pi_{3}-\pi_{3}\left(1-\pi_{T}\right) \exp \left(-\pi_{2}\left(1+\pi_{3}\right)\right)}{\left(1+\pi_{3}\right) \pi_{T}}
\end{aligned}
$$

By searching for the extremum of Equation (12) with respect to the variable $\pi_{2}$, according to the performed procedure, it is easily shown that the maximum exergy destruction is achieved for $\pi_{2 \text { stac,par }} \rightarrow \infty$, so its inclusion in Equation (12) gives the expression for maximum exergy destruction of a parallel-flow recuperator.

$$
\left(\frac{\Delta E x}{C_{1} T_{\mathrm{ok}}}\right)_{\text {par, } \max }=\ln \frac{\pi_{T}+\pi_{3}}{1+\pi_{3}}+\frac{1}{\pi_{3}} \ln \frac{\pi_{T}+\pi_{3}}{\left(1+\pi_{3}\right) \pi_{T}}
$$

\subsubsection{Counter-Flow Recuperator}

For the counter-flow recuperator, expressions for the local temperature of both streams are [25]

$$
\begin{gathered}
T_{1}=B_{1}+B_{2} \exp \left(-\pi_{3}\left(\pi_{3}-1\right) \frac{A}{A_{0}}\right) \\
T_{2}=B_{1}+\pi_{3} B_{2} \exp \left(-\pi_{3}\left(\pi_{3}-1\right) \frac{A}{A_{0}}\right)
\end{gathered}
$$

The constants $B_{1}$ and $B_{2}$ follow from the boundary conditions $A=0, T_{1}=T_{1 \text { in }}$, and $A=A_{0}, T_{2}=T_{2 \text { in }}$.

$$
B_{1}=\frac{\left(T_{1 \text { in }}-T_{2 \text { in }}\right) \exp \left(-\pi_{2}\left(1-\pi_{3}\right)\right)}{\exp \left(-\pi_{2}\left(1-\pi_{3}\right)\right)-\pi_{3}} ; B_{2}=\frac{T_{2 \text { in }} \exp \left(-\pi_{2}\left(1-\pi_{3}\right)\right)-\pi_{3} T_{1 \text { in }}}{\exp \left(-\pi_{2}\left(1-\pi_{3}\right)\right)-\pi_{3}}
$$

By including Equations (14) and (15) together with Equation (16) in Equation (3) and by carrying out the integration, the term for local exergy destruction of the counter-flow recuperator is obtained:

$$
\begin{gathered}
\left(\frac{\Delta E x\left(A / A_{0}\right)}{C_{1} T_{\mathrm{ok}}}\right)_{c o}=\ln \frac{\pi_{T}-\pi_{3} \exp \left(-\pi_{2}\left(1-\pi_{3}\right)\right)+\left(1-\pi_{T}\right) \exp \left(-\pi_{2}\left(1-\pi_{3}\right) \frac{A}{A_{0}}\right)}{1-\pi_{3} \exp \left(-\pi_{2}\left(1-\pi_{3}\right)\right)}+ \\
\frac{1}{\pi_{3}} \ln \frac{\pi_{T}-\pi_{3} \exp \left(-\pi_{2}\left(1-\pi_{3}\right)\right)+\left(1-\pi_{T}\right) \pi_{3}}{\pi_{T}-\pi_{3} \exp \left(-\pi_{2}\left(1-\pi_{3}\right)\right)+\left(1-\pi_{T}\right) \pi_{3} \exp \left(-\pi_{2}\left(1-\pi_{3}\right) \frac{A}{A_{0}}\right)}
\end{gathered}
$$

The total (global) exergy destruction is obtained for $A / A_{0}=1.0$.

$$
\begin{gathered}
\left(\frac{\Delta E x}{C_{1} T_{\mathrm{ok}}}\right)_{c o}=\ln \frac{\pi_{T}-\pi_{3} \exp \left(-\pi_{2}\left(1-\pi_{3}\right)\right)+\left(1-\pi_{T}\right) \exp \left(-\pi_{2}\left(1-\pi_{3}\right)\right)}{1-\pi_{3} \exp \left(-\pi_{2}\left(1-\pi_{3}\right)\right)}+ \\
\frac{1}{\pi_{3}} \ln \frac{\pi_{T}-\pi_{3} \exp \left(-\pi_{2}\left(1-\pi_{3}\right)\right)+\left(1-\pi_{T}\right) \pi_{3}}{\pi_{T}-\pi_{3} \exp \left(-\pi_{2}\left(1-\pi_{3}\right)\right)+\left(1-\pi_{T}\right) \pi_{3} \exp \left(-\pi_{2}\left(1-\pi_{3}\right)\right)}
\end{gathered}
$$

From Equations (17) and (18), a solution for a balanced counter-flow recuperator where $\pi_{3}=1.0$ is obtained:

$$
\left(\frac{\Delta E x\left(A / A_{0}\right)}{C_{1} T_{\text {ok }}}\right)_{c o, \pi_{3}=1.0}=\ln \frac{\pi_{2}\left(1-\pi_{T}\right) \frac{A}{A_{0}}+\pi_{2} \pi_{T}+\pi_{T}}{\pi_{T}\left(\pi_{2}+1\right)}+\ln \frac{\pi_{2}\left(1-\pi_{T}\right) \frac{A}{A_{0}}+\pi_{2} \pi_{T}+1}{\pi_{2} \pi_{T}+1}
$$


when $\pi_{2} \rightarrow \infty$, local and thus total exergy destruction $\rightarrow 0$, which means that heat transfer between streams in a balanced counter-flow recuperator takes place with vanishing temperature differences; i.e., such a balanced counter-flow recuperator hypothetically works reversibly.

The total exergy destruction of the balanced counter-flow recuperator is shown with Equation (20):

$$
\left(\frac{\Delta E x}{C_{1} T_{\mathrm{ok}}}\right)_{c o, \pi_{3}=1.0}=\ln \frac{\pi_{2}+\pi_{T}}{\pi_{2} \pi_{T}+\pi_{T}}-\ln \frac{\pi_{2}+1}{\pi_{2} \pi_{T}+1}
$$

In order to check whether Equation (18) has an extremum with respect to variable $\pi_{2}$, it is necessary to find a value $\left(\pi_{2}=\pi_{2 \text { stac }}\right)[26]$ :

$$
\pi_{2 \mathrm{stac}}=\frac{1}{1-\pi_{3}} \ln \frac{1}{\pi_{3}}
$$

Equation (21) shows that the value of $\pi_{2 \text { stac }}$ depends only on $\pi_{3}$, not on $\pi_{T}$.

By including Equation (21) in Equation (18), the expression for maximum exergy destruction in a counter-flow recuperator is obtained.

$$
\left(\frac{\Delta E x}{\dot{C}_{1} T_{\mathrm{ok}}}\right)_{c o, \max }=\ln \frac{\pi_{3}+\pi_{T}}{1+\pi_{3}}+\frac{1}{\pi_{3}} \ln \frac{\pi_{3}+\pi_{T}}{\pi_{T}\left(1+\pi_{3}\right)}
$$

By comparing Equations (13) and (22), it can be concluded that in both parallel-flow and counter-flow recuperators for the same $\pi_{\mathrm{T}}$ and $\pi_{3}$, the same values of maximum exergy destruction are achieved.

For a balanced counter-flow recuperator, the expression for $\pi_{2 \text { stac }}$ is obtained directly by searching for the extremum of the function in Equation (20) or by applying L'Hopital's rule to Equation (21).

$$
\pi_{2 \operatorname{stac}}\left(\pi_{3}=1.0\right)=1.0
$$

Returning (23) to Equation (20) gives the expression for the maximum exergy destruction of the balanced counter-flow recuperator.

$$
\left(\frac{\Delta E x}{\dot{C}_{1} T_{\text {ok }}}\right)_{c o, \max , \pi_{3}=1,0}=\ln \frac{\left(1+\pi_{T}\right)^{2}}{4 \pi_{T}}
$$

The principal question is what physically represents, in terms of changes in stream temperatures, the value $\pi_{2 \text { stac }}$. In order to answer this question, it is good to start from the case of a balanced counter-flow recuperator for which $\pi_{2 \mathrm{stac}}=1.0$ follows from Equation (23), and then from Equation (37) it follows that

$$
\varepsilon=\frac{\pi_{2 \mathrm{stac}}}{\pi_{2 \mathrm{stac}}+1}=\frac{1}{2}=0.50 .
$$

From Equation (7) and the energy balance of the balanced counter-flow recuperator, temperature $T_{1 \text { out }}$ equals

$$
T_{1 \text { out }}=T_{2 \text { out }}=\frac{T_{1 \text { in }}+T_{\text {in }}}{2}
$$

That is, the outlet temperatures of both streams in this case are equal to the arithmetic mean of the input stream temperatures, as qualitatively shown in Figure $2 b$. 


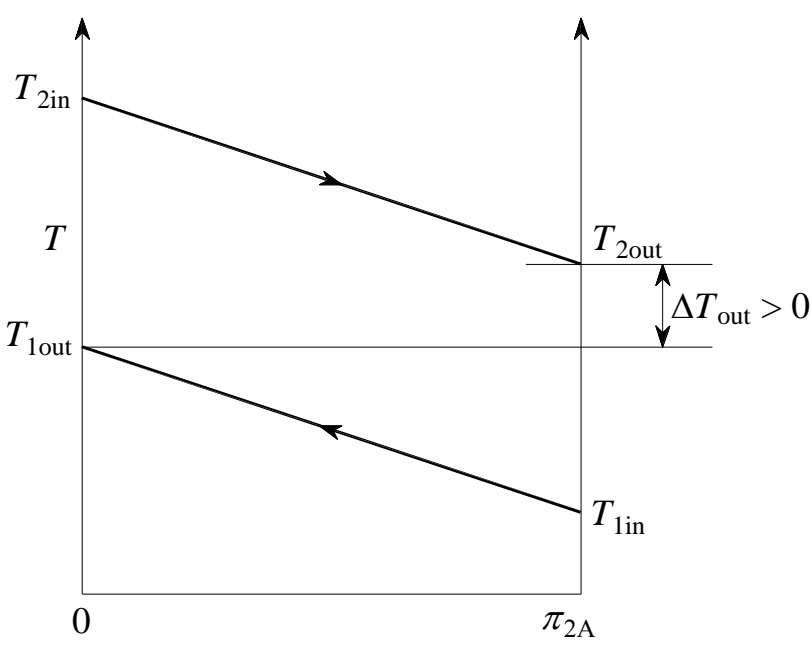

(a)

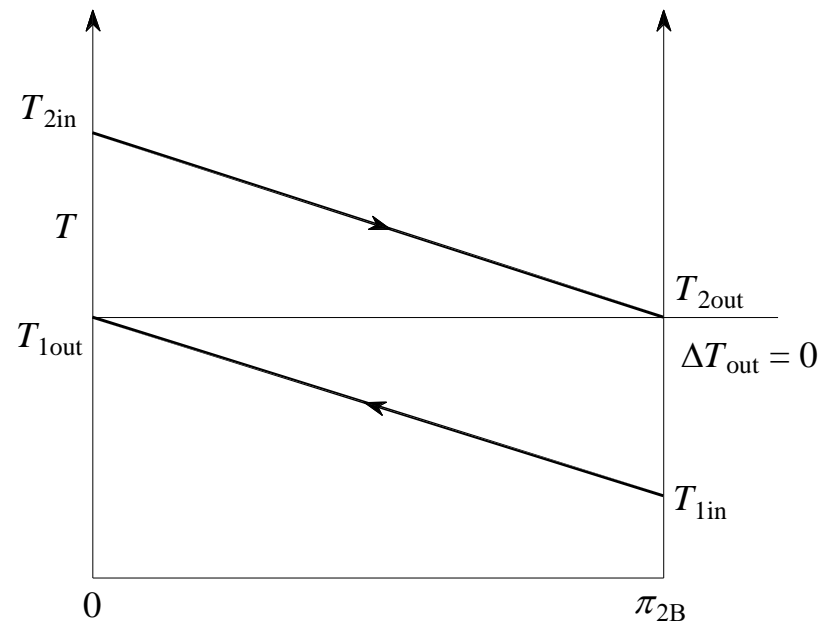

(b)

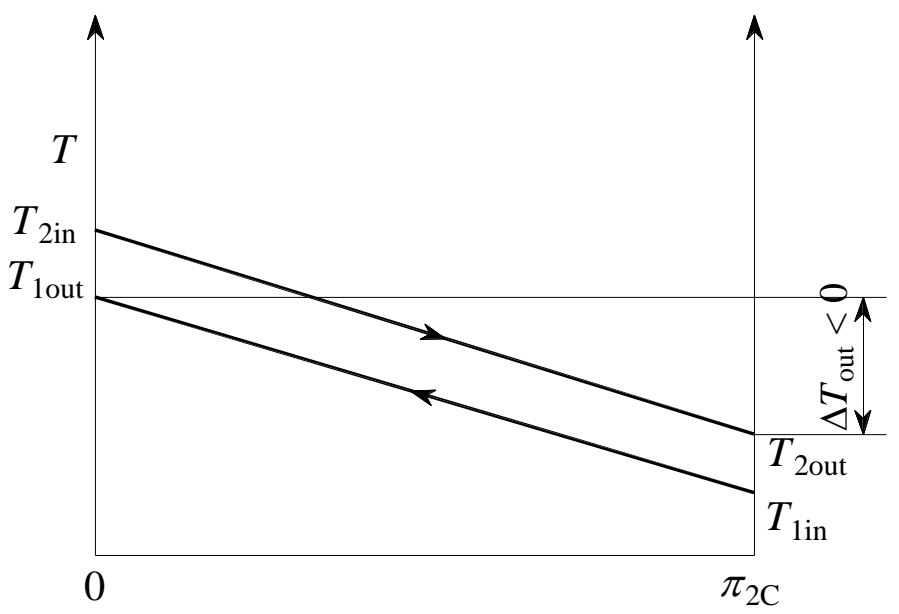

(c)

Figure 2. Characteristic $\pi_{2}$ values and temperature streams in the balanced counter-flow recuperators A, B and C: (a) $\Delta T_{\text {out }}>0$. (b) $\Delta T_{\text {out }}=0$. (c) $\Delta T_{\text {out }}<0$.

For a case where $\pi_{2 \mathrm{~A}}<\pi_{2 \mathrm{~B}}=1.0$, temperature distribution is shown qualitatively in Figure $2 \mathrm{a}$, and for a case where $\pi_{2 \mathrm{C}}>\pi_{2 \mathrm{~B}}=1.0$, temperature distribution is shown in Figure 2c.

Completely analogous phenomena also occur in other counter-flow recuperators where $\pi_{3} \neq 1.0$, shown in Figure 3a-c. For $\pi_{2}=\pi_{2 s t}$, equal outlet stream temperatures are obtained. Such temperatures would be obtained if the inlet streams were mixed in one adiabatic mixing chamber. According to this fact, the energy equation of the adiabatic mixing chamber is given, with a condition: $T_{\text {out }}=T_{1 \text { out }}=T_{2 \text { out }}$.

$$
\begin{gathered}
\dot{C}_{1} T_{1 \text { in }}+\dot{C}_{2} T_{2 \text { in }}=\left(\dot{C}_{1}+\dot{C}_{2}\right) T_{\text {out }} \\
T_{\text {out }}=\frac{\pi_{3} T_{1 \text { in }}+T_{2 \text { in }}}{1+\pi_{3}}
\end{gathered}
$$

Equation (27) refers to Figure 3b, which shows that the output temperatures of the weaker and stronger streams are equal. For this case, $\pi_{2 \mathrm{~B}}=\pi_{2 \mathrm{stac}}$ is determined by Equation (21). Case $\pi_{2 \mathrm{~A}}<\pi_{2 \mathrm{~B}}$ is shown in Figure $3 \mathrm{a}$, and case $\pi_{2 \mathrm{C}}>\pi_{2 \mathrm{~B}}$ is presented with Figure 3c. 


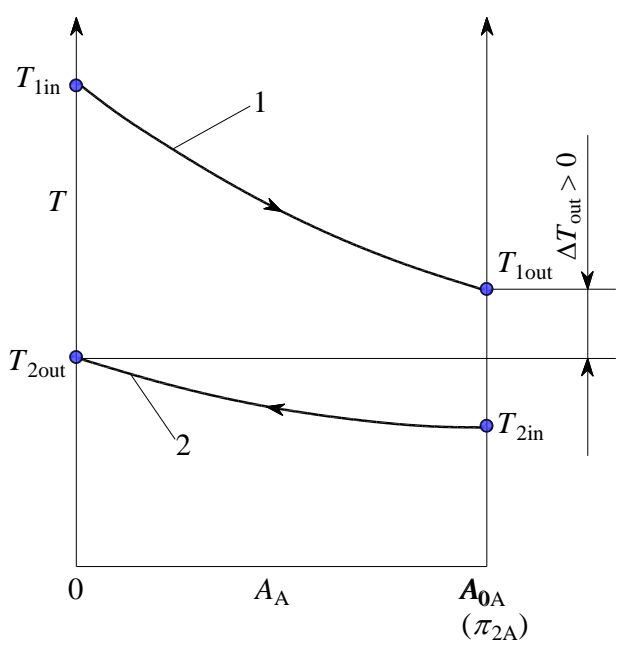

(a)

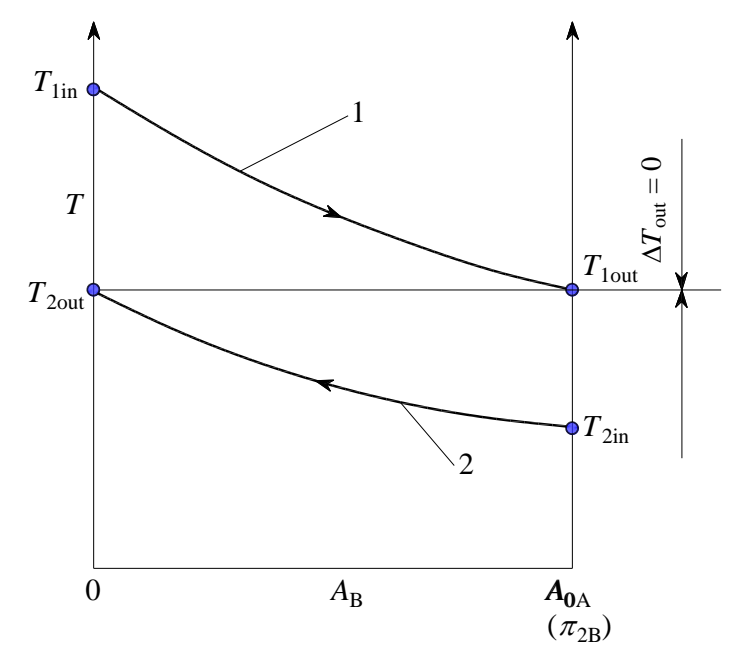

(b)

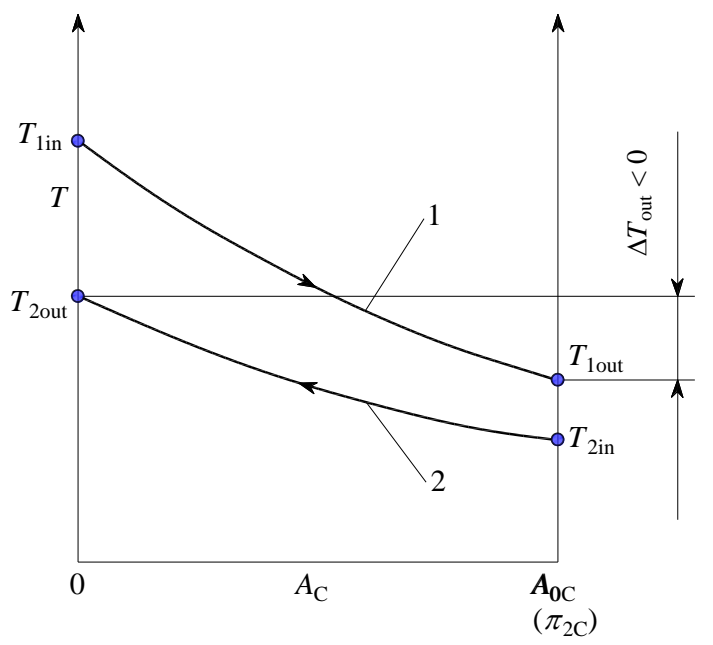

(c)

Figure 3. Characteristic $\pi_{2}$ values and temperature streams in the counter-flow recuperators $\mathrm{A}, \mathrm{B}$ and C: (a) $\Delta T_{\text {out }}>0$. (b) $\Delta T_{\text {out }}=0$. (c) $\Delta T_{\text {out }}<0$.

2.1.3. Solutions for the Case $\pi_{3}=0.0$

From the obtained solutions for the local and total exergy destruction for the parallelflow and counter-flow recuperators, a solution is easily reached for a case when the stronger stream evaporates or condenses $\left(\pi_{3}=0.0\right)$.

$\left(\frac{\Delta E x\left(A / A_{0}\right)}{\dot{C}_{1} T_{\mathrm{ok}}}\right)_{\pi_{3}=0.0}=\ln \left(\pi_{T}+\left(1-\pi_{T}\right) \exp \left(-\pi_{2} \frac{A}{A_{0}}\right)\right)+\frac{1-\pi_{T}}{\pi_{T}}\left(1-\exp \left(-\pi_{2} \frac{A}{A_{0}}\right)\right)$

When $A / A_{0}=1.0$, an expression for the total exergy destruction is obtained:

$$
\left(\frac{\Delta E x}{\dot{C}_{1} T_{\text {ok }}}\right)_{\pi_{3}=0.0}=\ln \left[1-\varepsilon\left(1-\pi_{T}\right)\right]+\varepsilon \frac{1-\pi_{T}}{\pi_{T}}
$$

Thus, the maximum of exergy destruction occurs in the counter-flow recuperator for the value of $\pi_{2 \text { stac }}$ which is determined by Equation (21), while for the parallel recuperator as well as the recuperator with phase change, this maximum occurs for $\pi_{2 \text { stac }} \rightarrow \infty$. 


\subsection{Total Exergy Destruction of All Basic Types of Heat Exchangers}

The previous overall solutions are also reached by the so-called global approach to the problem. Such an approach will provide a solution also for all forms of cross-flow recuperators. From the temperature flow of stream along the heat exchanger surface of the cross-flow recuperator, it is intuitively inferred that the finite values of $\pi_{2 s t a c}$ exist, for which maximum exergy destruction also occurs. In order to achieve this in general, the global exergy balance is set for the total heat exchanger area, shown in Figure 4.

$$
\Delta E x=E x_{1 \text { in }}-E x_{1 \text { out }}+E x_{2 \text { in }}-E x_{2 \text { out }}
$$

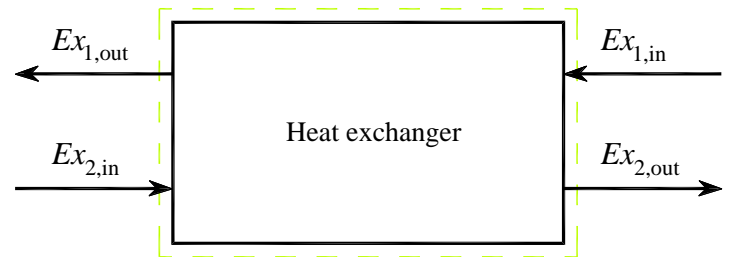

Figure 4. Exergy balance of the heat exchanger [26].

The change in exergy of the weaker stream, index 1 , and the change in exergy of the stronger stream, index 2, can be expressed as follows [27-30]:

$$
\begin{aligned}
& E x_{1 \text { in }}-E x_{1 \text { out }}=\dot{m}_{1}\left[c_{p 1}\left(T_{1 \text { in }}-T_{1 \text { out }}\right)-T_{\text {ok }} c_{p 1} \ln \frac{T_{1 \text { in }}}{T_{1 \text { out }}}\right] \\
& E x_{2 \text { in }}-E x_{2 \text { out }}=\dot{m}_{2}\left[c_{p 2}\left(T_{2 \text { in }}-T_{2 \text { out }}\right)-T_{\text {ok }} c_{p 2} \ln \frac{T_{\text {in }}}{T_{2 \text { out }}}\right]
\end{aligned}
$$

By including Equations (31) and (32) in Equation (30), the expression for exergy destruction can be changed to the following dimensionless form:

$$
\frac{\Delta E x}{\dot{C}_{1} T_{\text {ok }}}=\ln \frac{T_{1 \text { out }}}{T_{1 \text { in }}}+\frac{1}{\pi_{3}} \ln \frac{T_{2 \text { out }}}{T_{2 \text { in }}}
$$

By using Equations (4)-(7), it can be written in the following dimensionless form:

$$
\frac{\Delta E x}{\dot{\mathrm{C}}_{1} T_{\mathrm{ok}}}=\ln \left[1-\varepsilon\left(1-\pi_{T}\right)\right]+\frac{1}{\pi_{3}} \ln \left[1+\pi_{3} \varepsilon \frac{1-\pi_{T}}{\pi_{T}}\right]
$$

In the case of evaporator or condenser, Equation (34) is transformed into the following form:

$$
\left(\frac{\Delta E x}{\dot{C}_{1} T_{\mathrm{ok}}}\right)_{\pi_{3}=0.0}=\ln \left[1-\varepsilon\left(1-\pi_{T}\right)\right]+\varepsilon \frac{1-\pi_{T}}{\pi_{T}}
$$

For parallel-flow (par) and counter-flow (co) recuperators, the effectiveness $\varepsilon$ is given by the following equations [5,27-30]:

$$
\begin{gathered}
\varepsilon_{\text {par }}=\frac{1-\exp \left(-\left(1+\pi_{3}\right) \pi_{2}\right)}{1+\pi_{3}} \\
\varepsilon_{c o}=\frac{1-\exp \left(-\left(1-\pi_{3}\right) \pi_{2}\right)}{1-\pi_{3} \exp \left(-\left(1-\pi_{3}\right) \pi_{2}\right)}
\end{gathered}
$$

For a counter-flow recuperator, for which $\pi_{3}=1$.0, Equation (37) is transformed into

$$
\varepsilon_{p}\left(\pi_{3}=1.0\right)=\frac{\pi_{2}}{\pi_{2}+1}
$$


By including Equation (38) in Equation (34), the expression for exergy destruction of a balanced counter-flow recuperator is obtained:

$$
\left(\frac{\Delta E x}{C_{1} T_{\mathrm{ok}}}\right)_{\pi_{3}=1.0}=\ln \frac{\pi_{2}+\pi_{T}}{\pi_{2} \pi_{T}+\pi_{T}}-\ln \frac{\pi_{2}+1}{\pi_{2} \pi_{T}+1}
$$

This expression is identical to the expression in Equation (20). This means that Equation (34) is a significant equation that describes the total exergy destruction in all types of recuperators. In addition to the already shown parallel-flow and counter-flow recuperators, Equation (34) can also be applied to cross-flow recuperators.

In the case of a cross-flow recuperator, four cases should be distinguished:

1. Without mixing streamlines of weaker and stronger streams $(c r)$;

2. Mixing streamlines only of a weaker stream (cr1);

3. Mixing streamlines only of a stronger stream (cr2);

4. Mixing streamlines of both streams (cr12).

Effectiveness $\varepsilon$ for these types of cross-flow recuperators is expressed by the following equations [29]:

$$
\begin{gathered}
\varepsilon_{c r}=\pi_{1 c r}=1-\exp \left[\frac{\pi_{2}^{0.22}}{\pi_{3}}\left(\exp \left(-\pi_{3} \pi_{2}^{0.78}\right)-1\right)\right] \\
\varepsilon_{c r 1}=\pi_{1 c r 1}=1-\exp \left(-\frac{1-\exp \left(-\pi_{2} \pi_{3}\right)}{\pi_{3}}\right) \\
\varepsilon_{c r 2}=\pi_{1 c r 2}=\frac{1}{\pi_{3}}\left[1-\exp \left(-\pi_{3}\left(1-\exp \left(-\pi_{2}\right)\right)\right)\right] \\
\varepsilon_{c r 12}=\pi_{1 c r 12}=\frac{1}{\frac{1}{1-\exp \left(-\pi_{2}\right)}+\frac{\pi_{3}}{1-\exp \left(-\pi_{2} \pi_{3}\right)}-\frac{1}{\pi_{2}}}
\end{gathered}
$$

In the case of evaporator or condenser, from Equations (36), (37) and (40)-(43),

$$
\varepsilon_{\text {par }}=\varepsilon_{c o}=\varepsilon_{c r}=\varepsilon_{c r 1}=\varepsilon_{c r 2}=\varepsilon_{c r 12}=1-\exp \left(-\pi_{2}\right)
$$

which confirms the already known fact that in this case the effectiveness does not depend on the type of recuperator.

All equations for the effectiveness of the recuperator show that the value of the effectiveness of all recuperators equals zero for $\pi_{2}=0$, while for the hypothetical case $\pi_{2} \rightarrow \infty$ it depends on the type of recuperator and its effectiveness is shown with the following equations:

$$
\begin{gathered}
\varepsilon_{\text {par }}\left(\pi_{2} \rightarrow \infty\right)=\frac{1}{\pi_{3}+1} \\
\varepsilon_{c o}\left(\pi_{2} \rightarrow \infty\right)=\varepsilon_{c r}\left(\pi_{2} \rightarrow \infty\right)=1.0 \\
\varepsilon_{c r 1}\left(\pi_{2} \rightarrow \infty\right)=1-\exp \left(-\frac{1}{\pi_{3}}\right) \\
\varepsilon_{c r 2}\left(\pi_{2} \rightarrow \infty\right)=\frac{1-\exp \left(-\pi_{3}\right)}{\pi_{3}} \\
\varepsilon_{c r 12}\left(\pi_{2} \rightarrow \infty\right)=\frac{1}{1+\pi_{3}}
\end{gathered}
$$

The local extreme of the function in Equation (34) is given by the following expressions:

$$
\frac{\mathrm{d}}{\mathrm{d} \varepsilon}\left(\frac{\Delta E x}{\dot{C}_{1} T_{\mathrm{ok}}}\right)=\frac{\mathrm{d}}{\mathrm{d} \varepsilon}\left\{\ln \left[1-\varepsilon\left(1-\pi_{T}\right)\right]+\frac{1}{\pi_{3}} \ln \left[1+\pi_{3} \varepsilon \frac{1-\pi_{T}}{\pi_{T}}\right]\right\}=0
$$




$$
\begin{aligned}
& \varepsilon_{\text {stac }}=\frac{1}{1+\pi_{3}} \\
& \frac{\mathrm{d}^{2}}{\mathrm{~d} \varepsilon^{2}}\left[\left(\frac{\Delta E x}{\dot{C}_{1} T_{\text {ok }}}\right)\right]\left(\varepsilon_{\text {stac }}=\frac{1}{1+\pi_{3}}\right)=\frac{\left(1-\pi_{T}\right)^{2}\left(1+\pi_{3}\right)^{2}}{\left(\pi_{3}+\pi_{T}\right)^{2}}\left(\pi_{3}-1\right) \\
& \left(\frac{\Delta E x}{\dot{C}_{1} T_{\mathrm{ok}}}\right)_{\max }=\ln \frac{\pi_{3}+\pi_{T}}{1+\pi_{3}}+\frac{1}{\pi_{3}} \ln \frac{\pi_{3}+\pi_{T}}{\pi_{T}\left(1+\pi_{3}\right)} \\
& \left(\frac{\Delta E x}{\dot{C}_{1} T_{\text {ok }}}\right)=\ln \frac{T_{\text {out }}}{T_{1 \text { in }}}+\frac{1}{\pi_{3}} \ln \frac{T_{\text {out }}}{T_{2 \text { in }}}=\ln \frac{\frac{\pi_{3} T_{\text {1in }}+T_{2 \text { in }}}{1+\pi_{3}}}{T_{1 \text { in }}}+\frac{1}{\pi_{3}} \ln \frac{\frac{\pi_{3} T_{1 \text { in }}+T_{2 \text { in }}}{1+\pi_{3}}}{T_{2 \text { in }}}=\ln \frac{\pi_{3}+\pi_{T}}{1+\pi_{3}}+\frac{1}{\pi_{3}} \ln \frac{\pi_{3}+\pi_{T}}{\pi_{T}\left(1+\pi_{3}\right)}
\end{aligned}
$$

which is equal to expression in Equation (53).

Equation (53) is identical to Equations (13) and (22), so it shows that all basic types of recuperators have the same maximum exergy destruction with the same $\pi_{3}$ and $\pi_{T}$ values, where values of output stream temperatures are the same. The respective value of the output temperature of both streams corresponds to the value of the output temperature that would be obtained by adiabatic mixing of the streams.

Equation (53) can be further modified to two cases of recuperators; the first is the case for which $\pi_{3}=0.0$, and the second case refers to the counter-flow recuperator for which $\pi_{3}=1.0$.

$$
\left(\frac{\Delta E x}{\dot{C}_{1} T_{\text {ok }}}\right)_{\max , \pi_{3}=0.0}=\ln \left(\pi_{T}\right)+\frac{1-\pi_{T}}{\pi_{T}}
$$

The same form of the equation is obtained if the extreme of Equation (28) is required, from which it follows that $\varepsilon_{\text {stac }}=1.0$. By including this value in Equation (28), the expression in Equation (55) is obtained.

For the case of a counter-flow recuperator with $\pi_{3}=1.0$, the following expression is obtained:

$$
\left(\frac{\Delta E x}{\dot{C}_{1} T_{\text {ok }}}\right)_{c o \max , \pi_{3}=1.0}=\ln \frac{\left(1+\pi_{T}\right)^{2}}{4 \pi_{T}}
$$

which is equal to the derived expression shown in Equation (24).

Equation (51) shows that $\varepsilon_{\text {stac }}$ is the same for the given $\pi_{3}$ for all types of recuperators. Since $\varepsilon$, according to Equations (36)-(38) and (40)-(44), also depends on the type of recuperator, this means that each type of recuperator will have its corresponding $\pi_{2 \text { stac }}$ at which the maximum value of exergy destruction is achieved.

$$
\begin{gathered}
\pi_{2 \text { stac, par }}=\pi_{2 \text { stac, } \pi_{3}=0.0} \rightarrow \infty \\
\pi_{2 \text { stac, co }}=\frac{1}{1-\pi_{3}} \ln \left(\frac{1}{\pi_{3}}\right) \\
\pi_{2 \text { stac, co }}\left(\pi_{3}=1.0\right)=1.0
\end{gathered}
$$




$$
\begin{gathered}
\pi_{2 \text { stac, } c r 1}=\frac{1}{\pi_{3}} \ln \left(\frac{1}{1-\pi_{3} \ln \frac{1+\pi_{3}}{\pi_{3}}}\right) \\
\pi_{2 \text { stac, } c r 2}=\ln \left(\frac{\pi_{3}}{\pi_{3}-\ln \left(1+\pi_{3}\right)}\right)
\end{gathered}
$$

It is not possible to find an explicit solution for a cross-flow recuperator without mixing streamlines of weaker and stronger streams $(c r)$ or for a cross-flow recuperator in which weaker and stronger streams mix (cr12), due to the complexity of Equations (40) and (43), as can be seen from the following:

$$
\begin{gathered}
1-\exp \left[\frac{\pi_{2}^{0.22}}{\pi_{3}}\left(\exp \left(-\pi_{3} \pi_{2}^{0.78}\right)-1\right)\right]=\frac{1}{1+\pi_{3}} \\
\frac{1}{\frac{1}{1-\exp \left(-\pi_{2}\right)}+\frac{\pi_{3}}{1-\exp \left(-\pi_{2} \pi_{3}\right)}-\frac{1}{\pi_{2}}}=\frac{1}{1+\pi_{3}}
\end{gathered}
$$

The structure of Equations (62) and (63) shows that for the mentioned cases ( $c r$ and cr12), the value $\pi_{2 \text { stac }}$ must be found by a numerical procedure.

\subsection{The Ratio of Exergy Destruction to Recuperator Effectiveness}

The ratio of exergy destruction to recuperator effectiveness is shown with the following equation

$$
\frac{\Delta E x}{\dot{C}_{1} T_{\mathrm{ok}} \varepsilon}=\frac{\ln \left[1-\varepsilon\left(1-\pi_{T}\right)\right]}{\varepsilon}+\frac{1}{\pi_{3} \varepsilon} \ln \left[1+\pi_{3} \varepsilon \frac{1-\pi_{T}}{\pi_{T}}\right]
$$

For $\pi_{3}=0.0$, the above equation is transformed into the form

$$
\left(\frac{\Delta E x}{\dot{C}_{1} T_{\mathrm{ok}^{\varepsilon}}}\right)_{\pi_{3}=0.0}=\frac{\ln \left[1-\varepsilon\left(1-\pi_{T}\right)\right]}{\varepsilon}+\frac{1-\pi_{T}}{\pi_{T}}
$$

where the values of $\varepsilon$ are in the interval $0.0 \leq \varepsilon \leq \varepsilon\left(\pi_{2} \rightarrow \infty\right)$. The values of units $\varepsilon\left(\pi_{2} \rightarrow \infty\right)$ for individual types of recuperators are determined by Equations (45)-(49). For $\varepsilon=0.0$, Equation (64) is transformed into the following expression:

$$
\left(\frac{\Delta E x}{\dot{C}_{1} T_{\mathrm{ok}} \varepsilon}\right)(\varepsilon \rightarrow 0)=\frac{\left(1-\pi_{T}\right)^{2}}{\pi_{T}}
$$

By including the expression for $\pi_{T}$ in the above equation, according to Equation (5), the following expression is obtained:

$$
\left(\frac{\Delta E x}{\dot{C}_{1} T_{\mathrm{ok}} \varepsilon}\right)(\varepsilon \rightarrow 0)=\frac{\left(T_{1 \mathrm{in}}-T_{2 \mathrm{in}}\right)^{2}}{T_{1 \mathrm{in}} T_{2 \mathrm{in}}}
$$

It can be concluded that when the heat exchanger area tends to zero, expression (67) represents the maximum ratio of exergy destruction to recuperator effectiveness.

It is possible to explicitly express the magnitude of $\pi_{2}$ depending on $\varepsilon$ and $\pi_{3}$, so these functions are given for individual recuperators:

$$
\begin{gathered}
\pi_{2 p a r}=\frac{1}{1+\pi_{3}} \ln \frac{1}{\left[1-\varepsilon_{p a r}\left(1-\pi_{3}\right)\right]} \\
\pi_{2 c o}=\frac{1}{1-\pi_{3}} \ln \frac{1-\pi_{3} \varepsilon_{c o}}{1-\varepsilon_{c o}} \\
\pi_{2 c o}\left(\pi_{3}=1.0\right)=\frac{\varepsilon_{c o}}{1-\varepsilon_{c o}}
\end{gathered}
$$




$$
\begin{gathered}
\pi_{2 c r 1}=\frac{1}{\pi_{3}} \ln \frac{1}{1+\pi_{3} \ln \left(1-\varepsilon_{c r 1}\right)} \\
\pi_{2 c r 2}=\ln \frac{\pi_{3}}{\pi_{3}+\ln \left(1-\pi_{3} \varepsilon_{c r 2}\right)} \\
\pi_{2, \pi_{3}=0.0}=\ln \frac{1}{1-\varepsilon}
\end{gathered}
$$

For cross-flow recuperators ( $c r$ and $c r 12$ ), due to the structure of Equations (39) and (42), it is not possible to explicitly express the value of $\pi_{2}$.

\section{Results and Discussion}

\subsection{Presentation of Calculation Results for a Parallel-Flow Recuperator}

Diagrams in Figure 5a,b show the local and the total exergy destruction of a parallelflow heat exchanger for the selected values: $\pi_{T}=0.50$ and 2.0 and $\pi_{3}=1.0$.

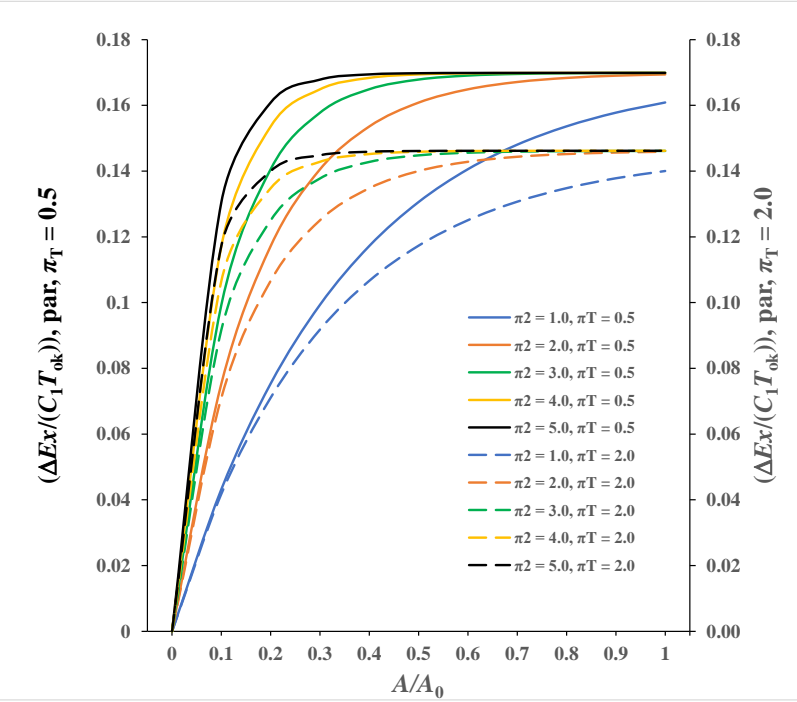

(a)

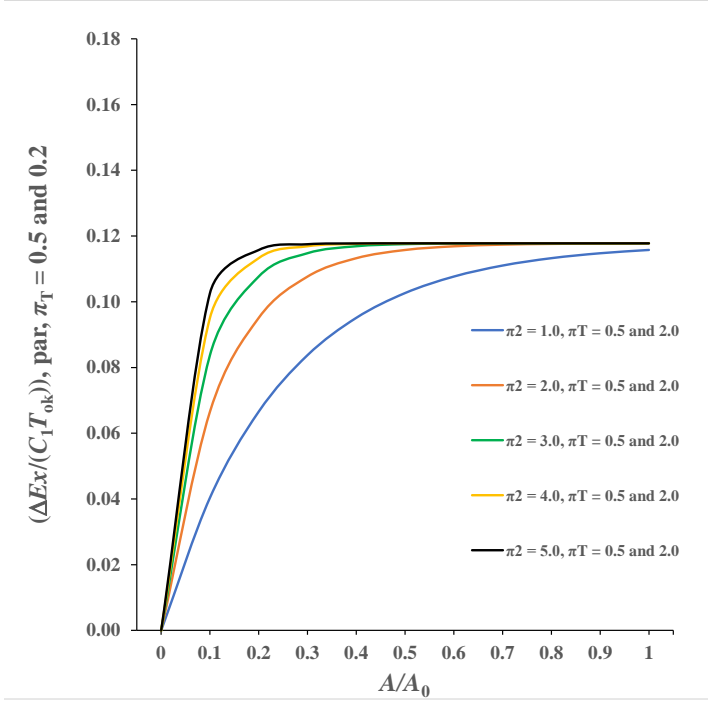

(b)

Figure 5. Local exergy destruction of a parallel-flow recuperator for $\pi_{T}=0.50$ and 2.0: (a) $\pi_{3}=0.50$; (b) $\pi_{3}=1.0$.

Figure 5a shows that in this case the local exergy destruction of the parallel recuperator increases continuously with the increase in the variable $A / A_{0}$, as well as with the increase in the variable $\pi_{2}$. It can also be seen from the same diagram that the values of exergy destruction are higher for $\pi_{T}=0.50$ (left ordinate axis, continuous lines) compared to $\pi_{T}=2.0$, which are shown on the right ordinate axis and with dashed lines. The values of total exergy destruction are read for individual $\pi_{2}$ at the abscissa $A / A_{0}=1.0$, and it can be seen that the values in question increase continuously with increasing $\pi_{2}$. However, it can also be seen that for $\pi_{T}=0.50$ and $\pi_{T}=2.0$, there are asymptotic (maximum) values of exergy destruction, which are 0.1699 and 0.1462 and are easily proven by Equation (13). It can be concluded that in both cases the respective asymptotic values are practically reached for values $\pi_{2} \geq 2$.0.

Figure $5 b$ shows the local and total exergy destruction for $\pi_{3}=1.0$ and $\pi_{T}=0.50$. These results are identical to results for $\pi_{3}=1.0$ and $\pi_{T}=2.0$. In this case, the maximum value of exergy destruction is 0.1178 , which is confirmed by the diagram in Figure $5 \mathrm{~b}$. In this case, the maximum (asymptotic) exergy destruction is practically achieved for $\pi_{2} \geq 2.0$ too, so according to the irreversibility criterion, there is no justification for the operating point of a parallel recuperator when $\pi_{2} \geq 2.0$. 


\subsection{Presentation of Calculation Results for a Counter-Flow Recuperator}

Diagrams in Figure $6 \mathrm{a}, \mathrm{b}$ show the local and the total exergy destruction of the counterflow recuperator for $\pi_{T}=0.50$ and 2.0 and $\pi_{3}=0.50$ and 1.0.

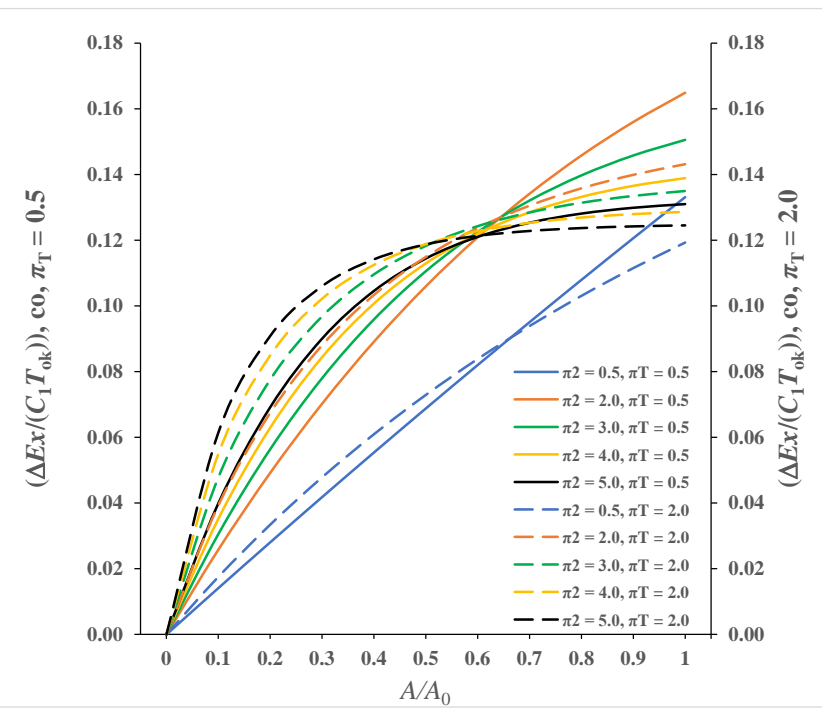

(a)

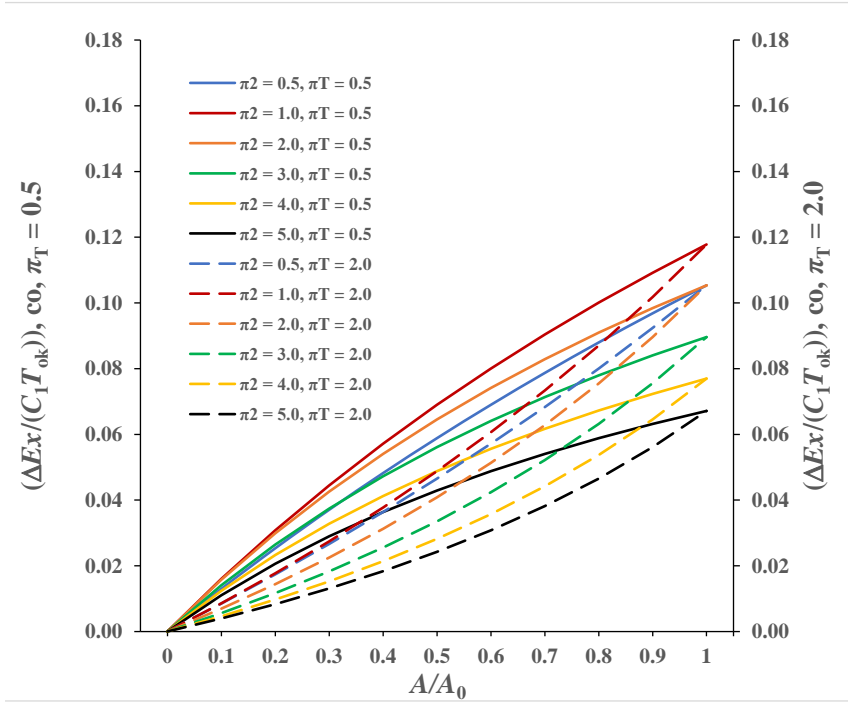

(b)

Figure 6. Local exergy destruction of a counter-flow recuperator for $\pi_{T}=0.50$ and 2.0: $(\mathbf{a}) \pi_{3}=0.50$; (b) $\pi_{3}=1.0$.

From the diagram in Figure $6 a, b$, it can be seen that the local exergy destruction continuously increases from the value 0.0 to the final value of the recuperator, which is determined by the magnitude $A / A_{0}=1.0$ with the corresponding $\pi_{2}$. It can be seen from both diagrams that the final total amount of exergy destruction first increases with increasing $\pi_{2}$, and then the value of exergy destruction decreases with a further increase in $\pi_{2}$. This means (confirmed with Equations (21), (57) and (58)) that with the counter-flow recuperator there is a final value $\pi_{2}=\pi_{2 \text { stac }}$ for which the maximum value of exergy destruction is achieved.

\subsection{Presentation of Calculation Results for a Recuperator for Which $\pi_{3}=0.0$}

Diagrams in Figure $7 \mathrm{a}, \mathrm{b}$ show the local and total exergy destruction for selected values $\pi_{T}=0.50$ and $\pi_{T}=2.0$ and indicated values of $\pi_{2}$, for recuperators where a stronger stream condenses or evaporates. In this case, as shown in Equations (28), (29), (43) and (55), the type of recuperator is completely irrelevant.

The diagram in Figure 7a shows that the value of local exergy destruction continuously increases from zero to the values achieved for $A / A_{0}=1.0$, with the corresponding $\pi_{2}$. The respective values are shown for the selected $\pi_{2}$ for the abscissa $A / A_{0}=1.0$ and are as follows: $0.2522,0.2894,0.3056,0.3067$ and 0.3068 . All curves tend to their asymptotic value determined by Equation (53), and this value for $\pi_{T}=0.50$ equals 0.30685 . This means that these types of recuperators have practically already reached the maximum exergy destruction for $\pi_{2} \geq 3.0$, and for these values the outlet temperature of the weaker stream, according to Equation (27), will practically achieve the value $T_{1 \text { out }}=T_{2 \text { in }}=T_{\text {sat }}$ that represents the saturation temperature of a stronger stream.

The situation is completely similar in Figure $7 \mathrm{~b}$, which refers to $\pi_{T}=2.0$. Total values of exergy destruction at $A / A_{0}=1.0$ are $0.1738,0.1907,0.1928,0.1931$ and 0.1931 , while the maximum value of exergy destruction for this case is 0.19315 . Maximum asymptotic values are explicitly confirmed by Equation (55). 


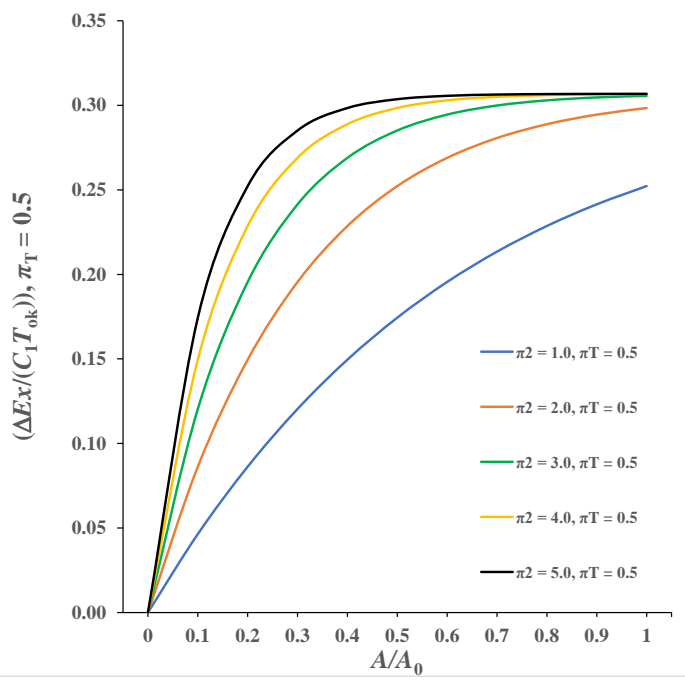

(a)

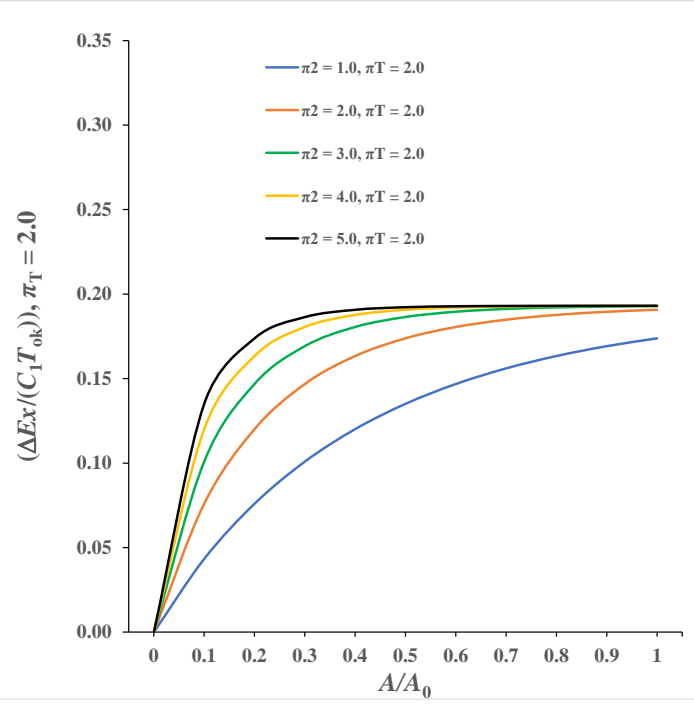

(b)

Figure 7. Local exergy destruction of a recuperator for $\pi_{3}=0.0$ : (a) $\pi_{T}=0.50 ;(\mathbf{b}) \pi_{T}=2.0$.

This analysis, as confirmed by the diagrams above, shows that it makes no sense to increase the $\pi_{2}$ value above 3.0, because such an unreasonable increase would lead to higher investment costs with a slight increase in recuperator effectiveness but with a significant (maximum) value of undesirable exergy destruction.

\subsection{Presentation of Recuperator Calculation Results by Variable $\pi_{2}$}

The algorithm for calculating the total exergy destruction of all basic recuperators represented with Equations (30)-(63) shows that for a significant variable it is convenient to choose $\pi_{2}$ so that the maximum exergy destructions for the values of $\pi_{2 \text { stac }}$ can be visible in the diagrams. These values are determined with Equations (57)-(63).

\subsubsection{Case $\pi_{3}=0.0$}

The diagram in Figure 8 shows the exergy destruction depending on $\pi_{2}$ and $\pi_{\mathrm{T}}$ in case the stronger stream changes its physical state. In the same diagram, the blue line shows the effectiveness of such a recuperator.

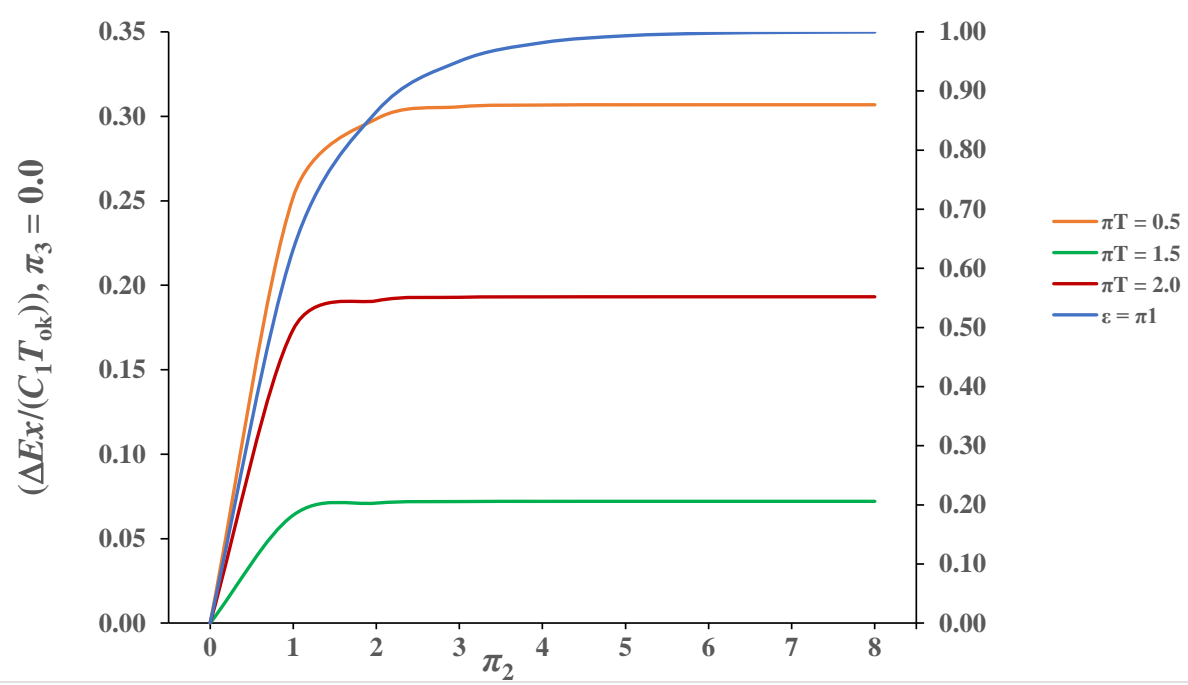

Figure 8. Dependence of exergy destruction on $\pi_{2}$ and $\pi_{T}$ with $\pi_{3}=0.0$. 
As already pointed out for this case, the type of recuperator has no effect on both the effectiveness and the amount of exergy destruction. The values of maximum exergy destruction are achieved relatively quickly; for $\pi_{T}=0.50,1.50$ and 2.0, they are 0.3069, 0.0721 and 0.1931 , respectively. It can be concluded that the working state of the recuperator with $\pi_{2}>3.0$ makes no sense because for this area the increase in recuperator effectiveness is relatively small, while exergy destruction is practically maximum.

\subsubsection{Case $\pi_{3} \neq 0.0$}

Each type of recuperator achieves different values of exergy destruction for $\pi_{3} \neq 0$, so the diagram in Figure 9a,b shows the values of exergy destruction for all types of recuperators depending on $\pi_{2}$, with selected values $\pi_{3}=\pi_{T}=0.50$.

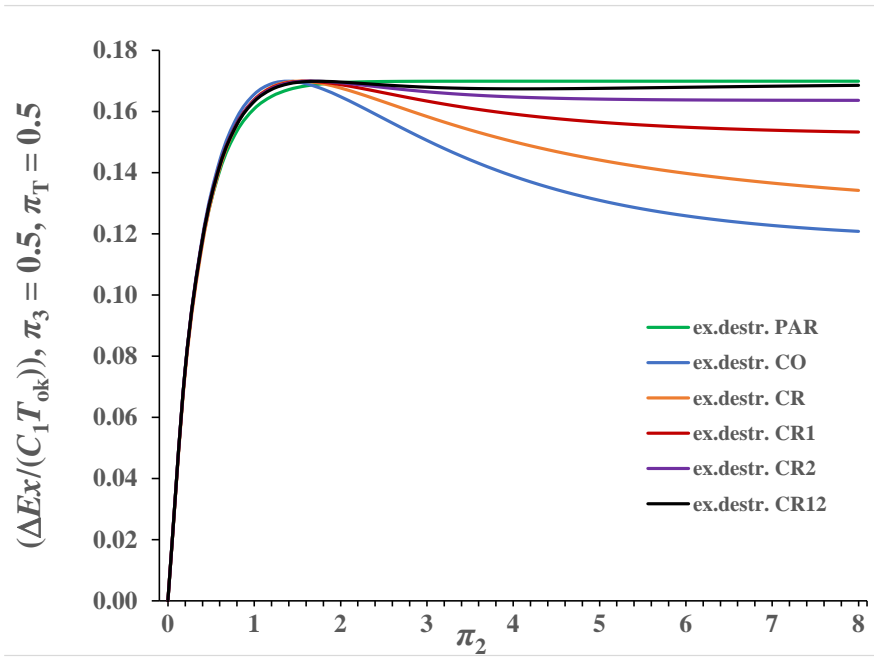

(a)

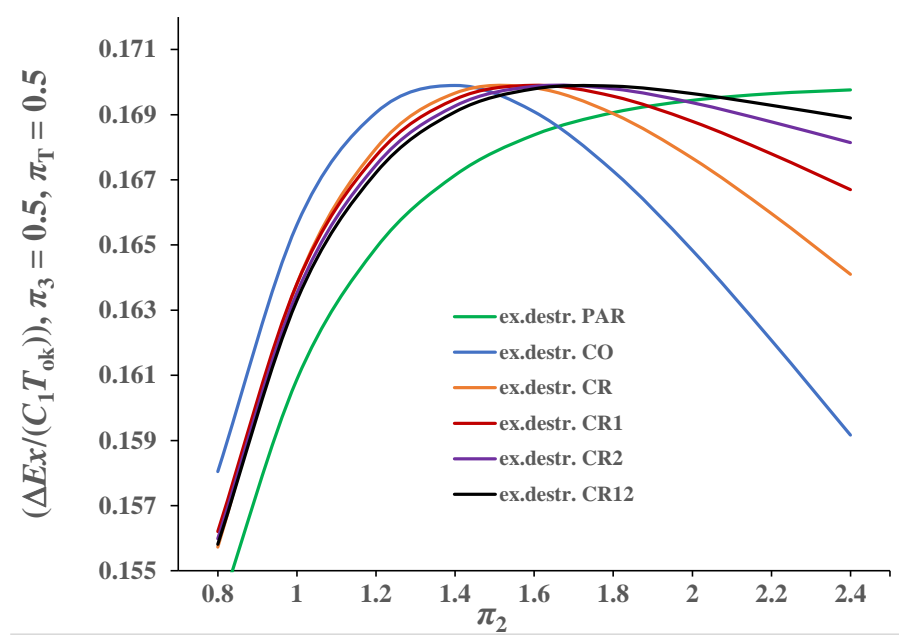

(b)

Figure 9. Dependence of exergy destruction on $\pi_{2}$ for $\pi_{T}=0.50$ and $\pi_{3}=0.50$ : (a) $0<\pi_{2}<8.0$; (b) $0.8<\pi_{2}<2.3$.

The characteristic behavior of exergy destruction is such that it first increases, reaches a maximum and then decreases, except for the parallel-flow recuperator where exergy destruction increases continuously with the increase in $\pi_{2}$. It is evident from the diagram, as shown in Equations (13), (22) and (53), that the achieved maxima, as local extremes, are the same for all types of recuperators and that maximum is 0.1699 , which is at the same time the maximum exergy destruction of the parallel recuperator for $\pi_{2} \rightarrow \infty$, which was practically reached for $\pi_{2}=2.60$. When $\pi_{3}$ equals 0.50 , then $\varepsilon_{\text {stac }}=2 / 3=0.667$ for all types of recuperators. Since the same values of $\pi_{T}$ are taken, according to Equation (53), the maximum values of exergy destruction must be equal. However, it can also be seen from the diagram in Figure 9a that the values of $\pi_{2 \text { stac }}$ are not equal for the observed types of recuperators, which is clearly visible in Figure $9 \mathrm{~b}$.

These stationary values were determined with Equations (57), (58), (60) and (61) for parallel-flow recuperator, counter-flow recuperator, cross-flow recuperator with mixing streamlines of weaker stream and cross-flow recuperator with mixing streamlines of stronger stream. These values are $\infty, 1.386,1.594$ and 1.666. Values $\pi_{2 \text { stac, } c r}=1.551$ and $\pi_{2 \text { stac, } \text { r } 12}=1.741$ are determined by numerical procedure. It can be seen from Figure $9 \mathrm{~b}$ that all cross-flow recuperators have mutually close values of exergy destruction for values $\pi_{2}<\pi_{2 \text { stac }}$, while more significant differences occur for $\pi_{2}>\pi_{2 \text { stac }}$.

Figure 10a,b represents results when $\pi_{3}=0.50$ and $\pi_{T}=2.0$. The behavior of the curves is like that in the previous case, with the difference that in this case lower values of exergy destruction were obtained. The values $\pi_{2 \text { stac }}$ in this observed case remained unchanged compared to the previous case because $\pi_{3}$ also equals 0.50 . Only the maximum 
value of exergy destruction decreased, which in this case, according to Equation (40), equals $\left(\Delta E x /\left(C_{1} T_{\mathrm{ok}}\right)\right)_{\max }=0.1462$.

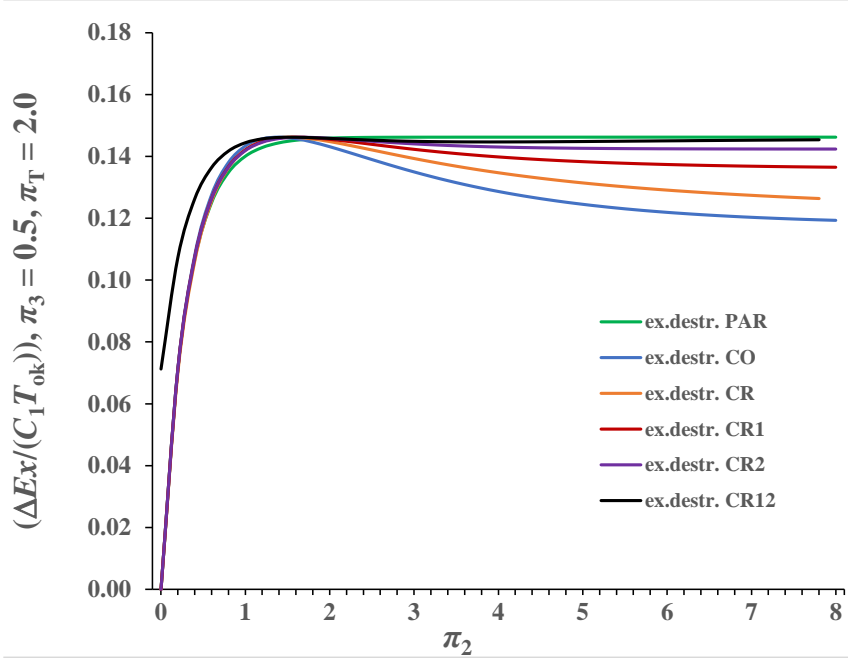

(a)

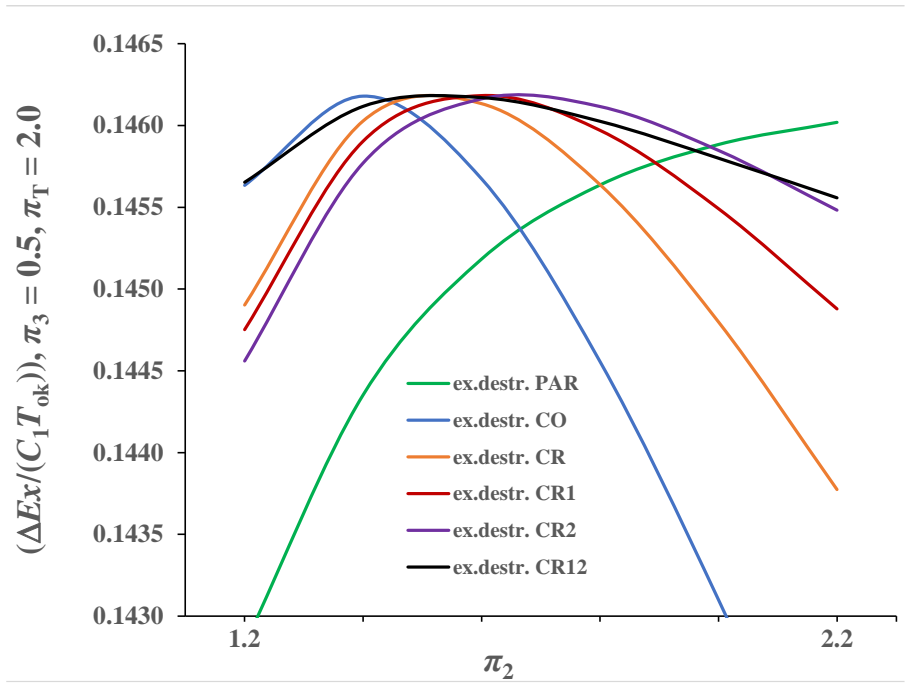

(b)

Figure 10. Dependence of exergy destruction on $\pi_{2}$ for $\pi_{T}=2.0$ and $\pi_{3}=0.50$ : (a) $0<\pi_{2}<8.0$; (b) $1.2<\pi_{2}<2.2$.

The diagrams in Figure 11a,b show the values of exergy destruction of all recuperators as a function of $\pi_{2}$ with $\pi_{T}=0.50$ and $\pi_{3}=1.0$. The obtained values of exergy destruction, using Equations (20) and (39), are lower than the values shown in Figure 9a,b and Figure 10a,b. It is interesting to note here that the obtained values of exergy destruction are equal for a cross-flow recuperator with mixing streamlines only of a weaker stream and for a cross-flow recuperator with mixing streamlines only of a stronger stream.

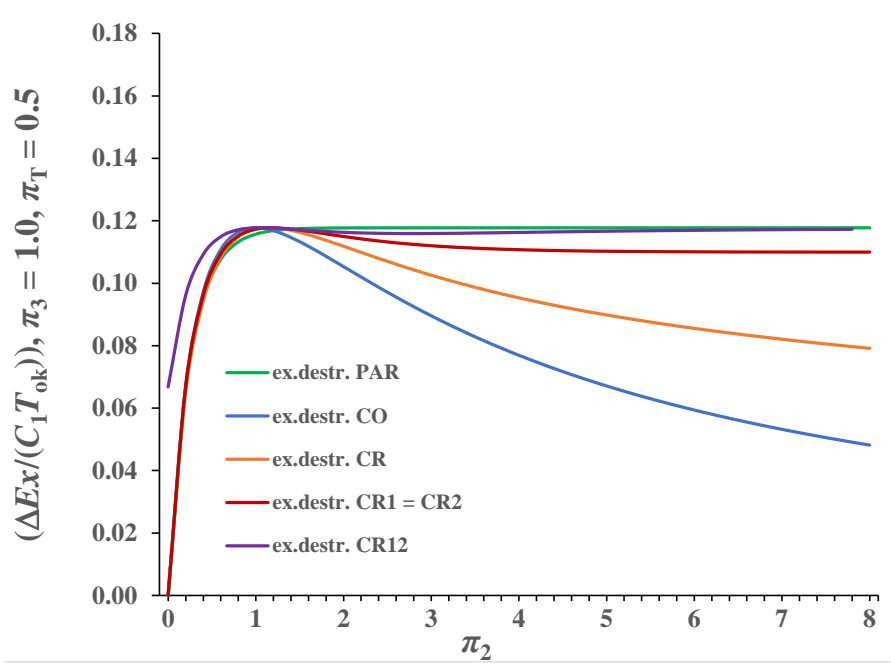

(a)

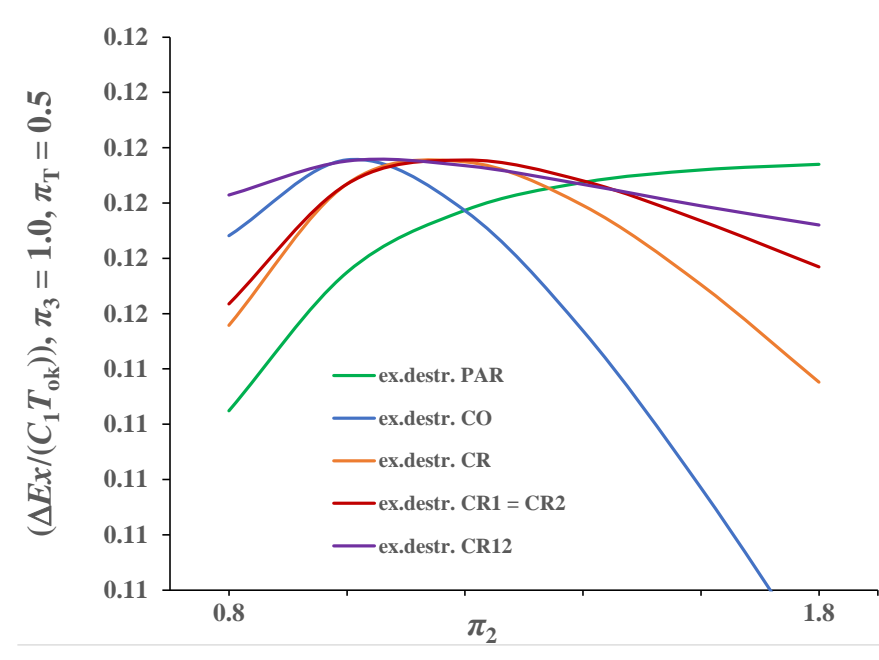

(b)

Figure 11. Dependence of exergy destruction on $\pi_{2}$ for $\pi_{T}=0.5$ and $\pi_{3}=1.0$ : (a) $0<\pi_{2}<8.0$; (b) $0.8<\pi_{2}<1.8$.

In this case as well, each type of recuperator reaches a local extreme maximum, for which the positions of the corresponding $\pi_{2 \text { stac }}$, together with the equal values of the maxima, are more clearly shown in Figure 11b. In this case, according to Equation (51), 
$\varepsilon_{\text {stac }}=0.50$, and the corresponding values of $\pi_{2 \text { stac }}$ for counter-flow and all cross-flow recuperators are 1.0, 1.15, 1.18, 1.18 and 1.23. The maximum value of exergy destruction, according to Equation (56), is 0.1178 .

It can be concluded that in the case of a parallel-flow recuperator and a recuperator with a phase change of a stronger stream, the maximum exergy destruction occurs when $\pi_{2} \rightarrow \infty$ because only in these cases are temperatures of the streams at the outlet equalized. For all other types of recuperators, maximum exergy destruction occurs at $\varepsilon_{\text {stac }}=1 /\left(1+\pi_{3}\right)$ because for the corresponding final value $\pi_{2 \text { stac }}$ the equality of output temperatures is realized, as shown for recuperator B in Figures $2 b$ and $3 b$.

As shown in Equations (57)-(61), value $\pi_{2 \text { stac }}$ for which the maximum exergy destruction is achieved depends for a given type of recuperator only on the $\pi_{3}$ and does not depend on the size $\pi_{T}$. Of course, the maximum value of exergy destruction in addition to the $\pi_{3}$, according to Equation (53), also depends on the $\pi_{T}$. These dependencies are shown in the diagram in Figure 12, which shows the results for counter-flow (co) and cross-flow ( $c r 1$ and $c r 2$ ) recuperators. For the cross-flow recuperators $c r$ and $c r 12$, numerical solutions are shown in Table 1.

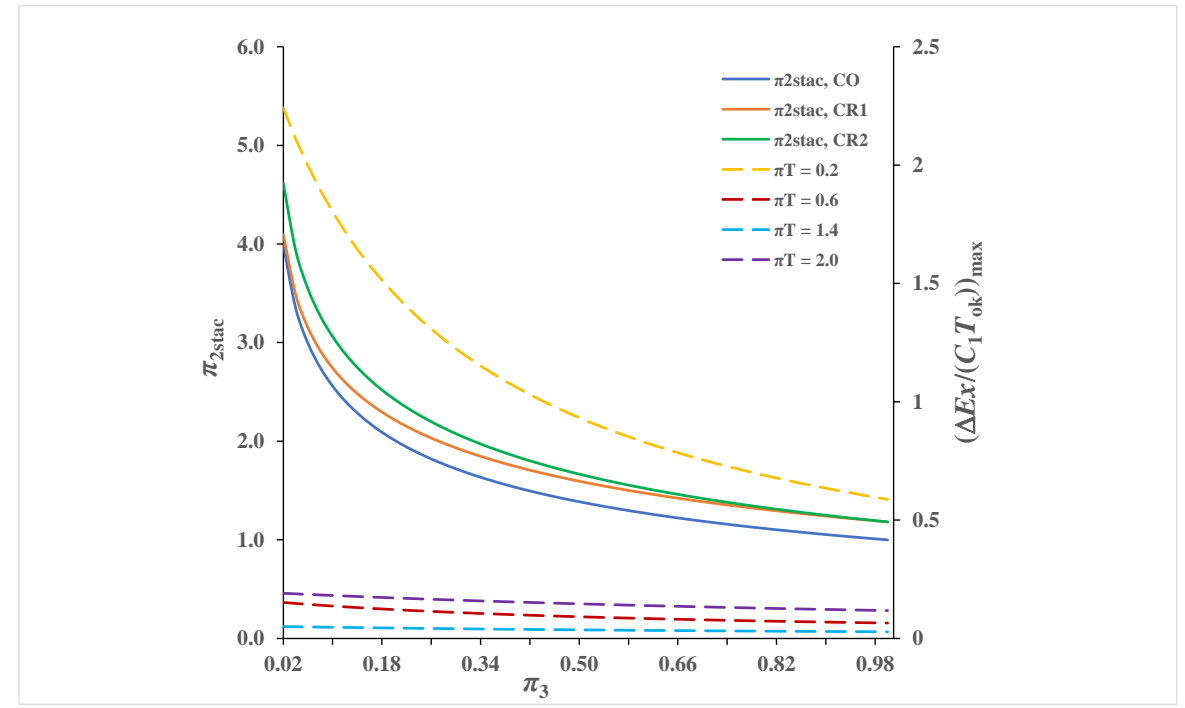

Figure 12. Dependence of $\pi_{2 \text { stac }}$ and $\left(\Delta E x /\left(C_{1} T_{\mathrm{ok}}\right)\right)_{\max }$ on $\pi_{T}$ and $\pi_{3}$.

Table 1. Dependence of $\pi_{2 \text { stac }}$ on $\pi_{3}$ for recuperators $c r$ and $c r 12$.

\begin{tabular}{ccc}
\hline$\pi_{3}$ & $\pi_{\text {2stac }}($ cr $)$ & $\pi_{\text {2stac }}($ cr 12$)$ \\
\hline 0.25 & 1.974 & 2.37 \\
0.50 & 1.520 & 1.74 \\
0.75 & 1.290 & 1.44 \\
1.00 & 1.150 & 1.26 \\
\hline
\end{tabular}

The diagram in Figure 12 shows that the values $\pi_{2 \text { stac }}$ continuously decrease with increasing $\pi_{3}$, from the value $\pi_{2 \text { stac }} \rightarrow \infty$ if $\varepsilon \rightarrow 0$, to the $\pi_{2 \text { stac }}\left(\varepsilon_{\max }=1.0\right)=1.0$ for the counter-flow recuperator $(c o)$, and up to the common value $\pi_{2 \text { stac }}\left(\varepsilon_{\max }=0.632\right)=1.1814$ for $\pi_{3}=1.0$ for both cross-flow recuperators ( $\left.c r 1\right)$ and ( $\left.c r 2\right)$. This is in accordance with Equations (47) and (48) which become identical for $\pi_{3}=1.0$. Furthermore, it can be concluded that for the same values of $\pi_{3}$, values of $\pi_{2 \text { stac }}$ are the lowest in the counter-flow recuperator $(\mathrm{co})$, slightly higher in the cross-flow recuperator ( $c r 1)$ and highest in the cross-flow recuperator (cr2).

Dashed lines in Figure 12 show the maximum values of exergy destruction depending on $\pi_{3}$ and $\pi_{T}$ and which are equal, according to Equation (53), for all types of recupera- 
tors. The diagram shows that the maximum value of exergy destruction decreases with increasing $\pi_{3}$ and with increasing $\pi_{T}$ if $\pi_{T}$ increases from 0 to 1.0.

\subsection{Presentation of the Ratio of Exergy Destruction to Effectiveness of the Recuperator}

\subsubsection{Case $\pi_{3}=0.0$}

The diagram in Figure 13a,b shows the exergy destruction as well as the ratio of exergy destruction to effectiveness of the recuperator in the case when a stronger stream evaporates or condenses. The value of $\varepsilon$ is between 0.0 and 1.0. The value of these quantities is independent of the type of recuperator, which results from Equations (29) and (65). The maximum value of exergy destruction, according to Equation (55), is achieved at $\varepsilon_{\text {stac }}$ $=1.0$, which is in accordance with the diagram in Figure 13a,b, where continuous lines end with a horizontal tangent for $\varepsilon=1.0$. For selected values $\pi_{T}=0.2,0.3,0.4,0.5$ and 0.6 , the respective maximum values are 2391, 1129, 0.584, 0.307 and 0.156. Dashed lines in Figure 13a show, according to Equations (65) and (66), values of the ratio of exergy destruction to effectiveness of the recuperator. This value, for a given $\pi_{T}$, continuously decreases from the value determined with Equation (66) for $\varepsilon=0.0$ to a value equal to maximum values of exergy destruction for $\varepsilon=1.0$. Values of this ratio for $\varepsilon=0.0$ with $\pi_{T}=0.2,0.3,0.4,0.5$ and 0.6 respectively are $3.20,1.633,0.90,0.50$ and 0.267 ; for $\varepsilon=1.0$, the respective values are, according to Equation (65), as follows: 2.391, 1.129, 0.584, 0.307 and 0.156 .

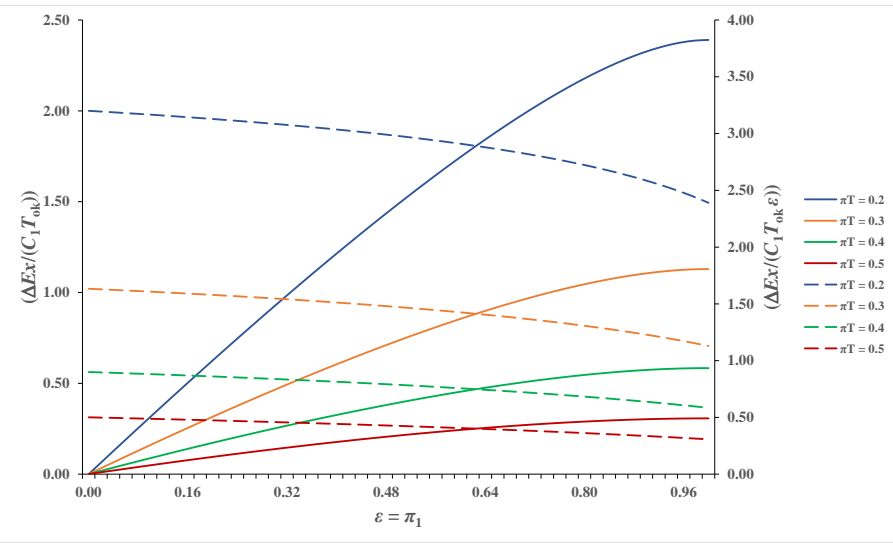

(a)

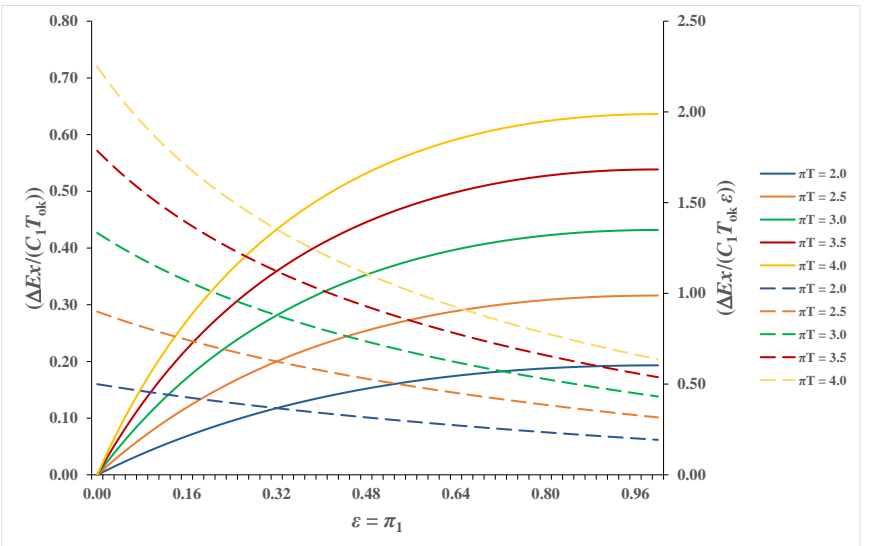

(b)

Figure 13. Dependence of exergy destruction and the ratio of exergy destruction to effectiveness of the recuperator on $\varepsilon$ and $\pi_{T}$ for $\pi_{3}=0.0$ : (a) $0.2<\pi_{T}<0.5$; (b) $2.0<\pi_{T}<4.0$.

Calculation results in Figure 13b represent the cases when $\pi_{T}>1.0$ for selected values $\pi_{T}=2.0$ to 4.0 with a step of 0.5 . The left ordinate axis represents the values of exergy destruction, and the right ordinate axis represents the ratio of exergy destruction to effectiveness of the recuperator. Exergy destruction increases with the increase in $\varepsilon$ from the value of zero to the maximum value that is determined with Equation (24). It is evident that in this case exergy destruction increases with increasing $\pi_{T}$. The maximum values of exergy destruction, for selected $\pi_{T}=2.0$ to 4.0 , are $0.193,0.316,0.432,0.538$ and 0.636 . The right ordinate axis, related to the dashed lines, in Figure 13b, shows the ratio of exergy destruction to effectiveness of the recuperator as a function of $\varepsilon$ and $\pi_{T}$. It can be seen from the diagram that here too the ratio decreases with increasing $\varepsilon$ and with decreasing $\pi_{T}$. The ratio values for $\varepsilon=0.0$ for the selected $\pi_{T}$ according to Equation (66) are 0.50, 0.90, 1.33, 1.78 and 2.25. The values of this ratio for $\varepsilon=1.0$ are identical to the values of maximum exergy destruction indicated above. It is evident that with increasing $\pi_{T}$ there is a greater change in the ratio of exergy destruction to effectiveness of the recuperator. 


\subsubsection{Case $\pi_{3} \neq 0.0$}

In cases with $\pi_{3} \neq 0$, the type of recuperator will be relevant both to the value of exergy destruction and to the value of the ratio of exergy destruction to effectiveness of the recuperator.

The diagrams in Figure 14a,b show the exergy destruction and the relevant ratio for $\pi_{3}=0.25$.

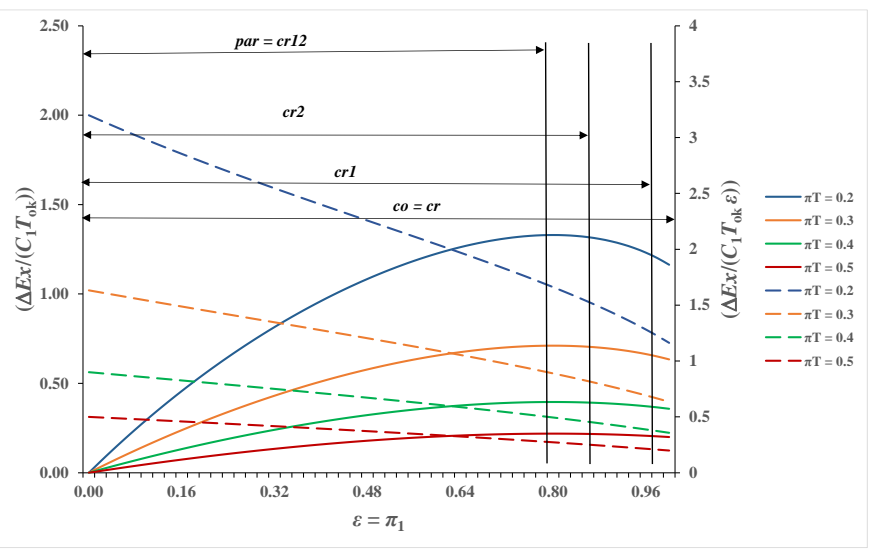

(a)

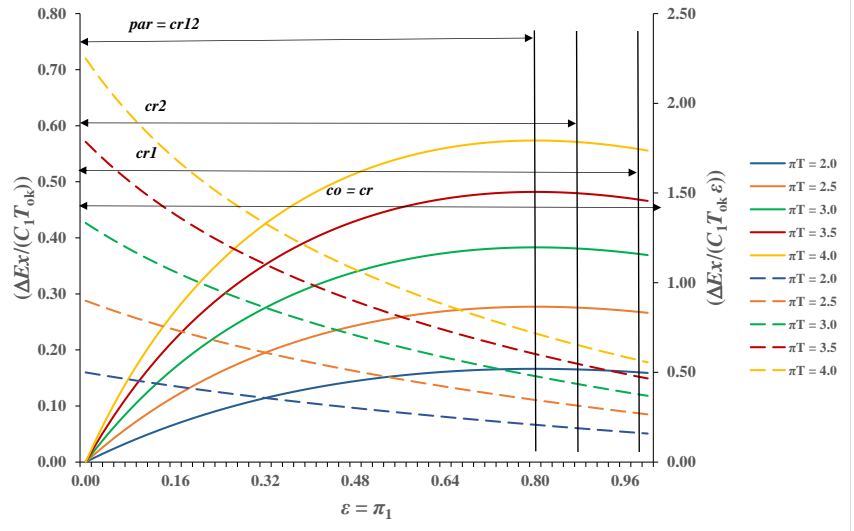

(b)

Figure 14. Dependence of exergy destruction and the ratio of exergy destruction to effectiveness of the recuperator on $\varepsilon$ and $\pi_{T}$ for $\pi_{3}=0.25$ : (a) $0.2<\pi_{T}<0.5$; (b) $2.0<\pi_{T}<4.0$.

The diagram in Figure 14a shows exergy destruction (continuous lines) and ratio (dashed lines) as a function of $\varepsilon$ and $\pi_{T}$ where $0.20 \leq \pi_{T} \leq 0.60$ with a step of 0.10 . It is interesting to note the fact that each parametric curve $\pi_{T}=$ const. has its own constraint related to the type of recuperator, so for parallel-flow (par) and cross-flow (cr12) recuperators, solutions apply only to the interval $0 \leq \varepsilon \leq 0.80=\varepsilon_{\text {stac }}$, since $\varepsilon_{\text {stac }}$ equals 0.80 for all types of recuperators, according to Equation (51) and when $\pi_{3}$ equals 0.25 . For the value of $\varepsilon_{\text {stac }}=0.80$ and the corresponding $\pi_{T}$, according to Equation (53), all recuperators achieve the same value of the maximum exergy destruction and thus the same value of the ratio. Due to the value of $\varepsilon_{\text {stac }}=0.80$ for parallel-flow (par) and cross-flow ( $\left.c r 12\right)$ recuperators, values greater than $\varepsilon_{\text {stac }}$ can no longer refer to those types of recuperators. The constraint for cross-flow recuperator $c r 2$ equals 0.885 , and that for cross-flow recuperator $c r 1$ is 0.982 while entire interval of $\varepsilon$ refers to the counter-flow $(c o)$ and cross-flow ( $c r)$ recuperators. All these values are indicated by vertical lines in Figure 14a,b.

The diagrams in Figure 14a,b show that the value of exergy destruction continuously increases from zero to maximum with $\varepsilon$ increasing from zero to $\varepsilon_{\text {stac }}=0.80=\varepsilon_{\max }$ for parallel-flow (par) and cross-flow (cr12) recuperators. The values of these maxima decrease with increasing $\pi_{T}$, as shown in Figure 14 a, but further increase with increasing $\pi_{T}$, as shown in Figure 14b. For all other cases, the values of exergy destruction reach the same maximum for a given $\pi_{T}$ and further decrease to the values shown at the ends $c r 2, c r 1$ and $c r=c o$. These values can be easily read from the diagrams.

The diagrams in Figure 15 show a clearer meaning of the stated restrictions of individual recuperator types. Figure $15 \mathrm{a}, \mathrm{b}$ represents the dependence of $\pi_{2}$ on effectiveness for selected recuperators when $\pi_{3}=0.25$. It is evident from these diagrams that for $0 \leq \varepsilon \leq \varepsilon_{\text {stac }}=0.80$ and for the same $\varepsilon$ and $\pi_{3}$ value, $\pi_{2 p a r}>\pi_{2 k 2}>\pi_{2 k 1}>\pi_{2 c o}$. This means that for the same values of heat transfer coefficient and heat capacity of the weaker stream there will be the following connection between heat exchanger area of the observed recuperators: $A_{0 p a r}>A_{0 c r 2}>A_{0 c r 1}>A_{0 \mathrm{co}}$. 


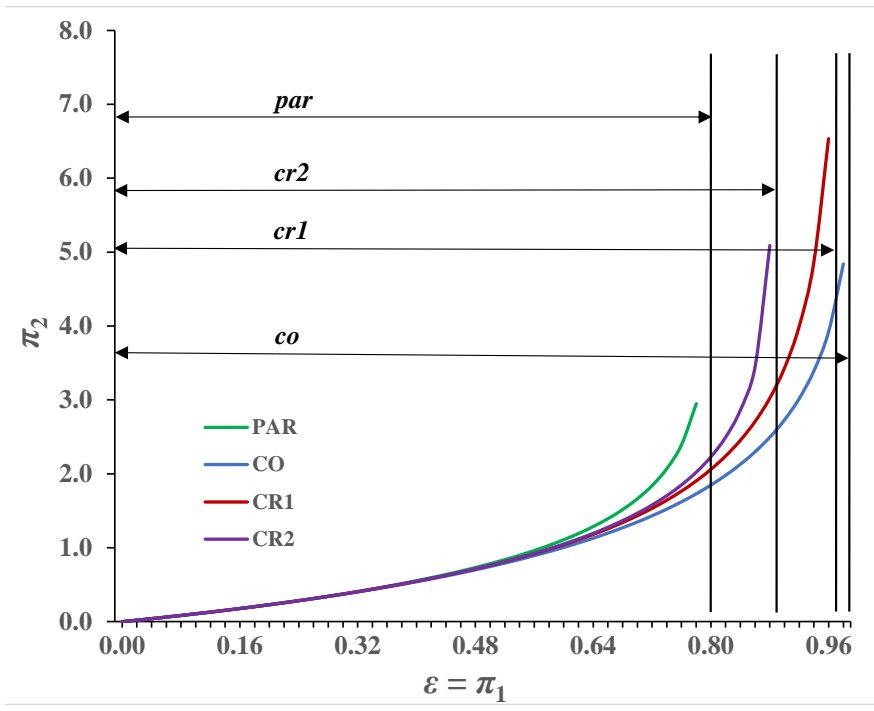

(a)

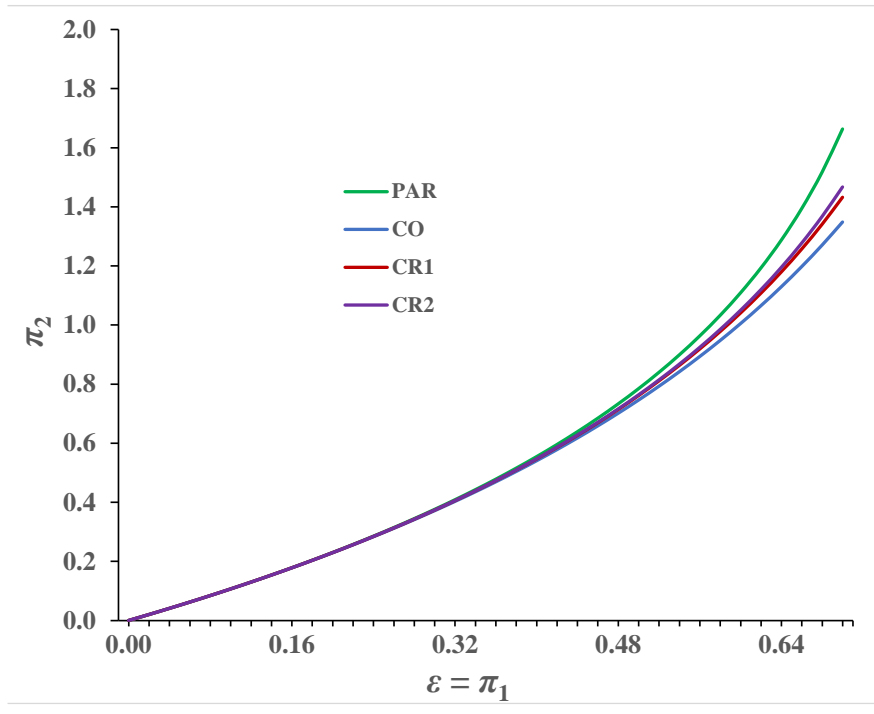

(b)

Figure 15. Dependence of $\pi_{2}$ on effectiveness of recuperator with $\pi_{3}=0.25$ : (a) $0<\varepsilon<1.0$; (b) $0<\varepsilon<0.7$.

\section{Conclusions}

The paper presents dimensionless exergy destruction and the ratio of exergy destruction to effectiveness of a heat exchanger for all basic types of recuperators. The most important findings are as follows:

- The obtained expressions enable detailed analysis of the quantitative influence of the dimensionless quantities $\pi_{1}=\varepsilon, \pi_{2}, \pi_{3}$ and $\pi_{T}$ both on the amount of exergy destruction and on the amount of the ratio of exergy destruction to effectiveness of the respective recuperator.

- For all recuperators, derived analytical expressions explicitly determine the effectiveness of the recuperator $\varepsilon_{\text {stac }}=1 /\left(1+\pi_{3}\right)$ for which the maximum of exergy destruction occurs as a local extreme.

- With the presented algorithm, it is possible to determine the operating point of the heat exchanger if either the value of dimensionless exergy destruction or the value of the ratio of exergy destruction to effectiveness is given as a criterion. For a given type of recuperator, the parameters of the recuperator operating point should be selected in a way that $\pi_{2}$ is greater than $\pi_{2 \text { stac }}$, because in that case the exergy destruction is less than maximum and the value of the effectiveness is greater, which leads to the desired reduction in the ratio of exergy destruction to effectiveness.

- For the parallel-flow and counter-flow recuperators, a local approach to the solution of exergy destruction is presented. This enables other local effects (such as stream pressure drop) to be built into this algorithm, with the optimization of local exergy destruction as a goal, involving more relevant effects. Moreover, it is possible to quantify the exergy destruction and the ratio of exergy destruction to effectiveness in respect to a higher number of streams passing through the heat exchanger [31], which is more often the practical case.

Author Contributions: Conceptualization, M.R. and A.G.; methodology, A.G. and M.R.; formal analysis, A.G.; investigation, M.R. and S.M.; writing—original draft preparation, M.R.; writingreview and editing, A.G. and S.M.; visualization, M.R. and S.M.; supervision, A.G. All authors have read and agreed to the published version of the manuscript.

Funding: This research received no external funding.

Institutional Review Board Statement: Not applicable.

Informed Consent Statement: Not applicable. 


\section{Data Availability Statement: Not applicable.}

Conflicts of Interest: The authors declare no conflict of interest.

\section{References}

1. Bošnjaković, F. Kampf den nichtumkehrbarkeiten. Arch. Wärmewirtsch. Dampfkesselwes. 1938, 19, 1-2.

2. Rant, Z. Exergie, ein neues wort für technische arbeitsfähigkeit. Forsch. Geb. Ing. 1956, 22, 36-37.

3. Gouy, M. Sur l'énergie utilizable. J. Phys. 1889, 8, 501-518.

4. Stodola, A. Steam and Gas Turbines, 1st ed.; McGraw-Hill: New York, NY, USA, 1910.

5. Bejan, A. Fundamentals of exergy analysis, entropy generation minimization, and the generation of flow architecture. Int. J. Energy Res. 2006, 26, 545-565. [CrossRef]

6. Yilmaz, M.; Sara, O.N.; Karsli, S. Performance evaluation criteria for heat exchangers based on second law analysis. Int. J. Exergy 2001, 4, 278-294. [CrossRef]

7. Manjunath, K.; Kaushik, S.C. Second law thermodynamic study of heat exchangers: A review. Renew. Sustain. Energy Rev. 2014, 40, 348-374. [CrossRef]

8. Sepehr, M.; Hashemi, S.S.; Rahjoo, M.; Farhangmehr, V.; Alimoradi, A. Prediction of heat transfer, pressure drop and entropy generation in shell and helically coiled finned tube heat exchangers. Chem. Eng. Res. Des. 2018, 134, 277-291. [CrossRef]

9. Genić, S.; Jaćimović, B.; Petrović, A. A novel method for combined entropy generation and economic optimization of countercurrent and co-current heat exchangers. Appl. Therm. Eng. 2018, 136, 327-334. [CrossRef]

10. Guzmán, J.E.V.; Hernández-Arrieta, I.; Vicente, W.; Salinas-Vazquez, M.; Martínez-Espinosa, E. Non-local entropy evolution in heat exchangers with elliptical and circular tube geometries. Int. J. Therm. Sci. 2018, 134, 601-611. [CrossRef]

11. Goh, L.H.K.; Hung, Y.M.; Chen, G.M.; Tso, C.P. Entropy generation analysis of turbulent convection in a heat exchanger with self-rotating turbulator inserts. Int. J. Therm. Sci. 2021, 106, 106652. [CrossRef]

12. Etghani, M.M.; Baboli, S.A.H. Numerical investigation and optimization of heat transfer and exergy loss in shell and helical tube heat exchanger. Appl. Therm. Eng. 2017, 121, 294-301. [CrossRef]

13. Wang, J.; Hashemi, S.S.; Alahgholi, S.; Mehri, M.; Safarzadeh, M.; Alimoradi, A. Analysis of exergy and energy in shell and helically coiled finned tube heat exchangers and design optimization. Int. J. Refrig. 2018, 94, 11-23. [CrossRef]

14. Alimoradi, A. Investigation of exergy efficiency in shell and helically coiled tube heat exchangers. Case Stud. Therm. Eng. 2017, 10, 1-8. [CrossRef]

15. Al-Salem, K.; Hosseini, E.; Nohesara, A.; Mehri, M.; Ali, M.; Almuzaiqer, R.; Alimoradi, A.; Tlili, I. Suggestion of new correlations for the exergy efficiency and coefficient of exergy performance of annulus section of conically coiled tube-in-tube heat exchangers. Chem. Eng. Res. Des. 2019, 152, 309-319. [CrossRef]

16. Wilhelmsen, Ø.; Berstad, B.; Aasen, A.; Nekså, P.; Skaugen, G. Reducing the exergy destruction in the cryogenic heat exchangers of hydrogen liquefaction processes. Int. J. Hydrogen Energy 2018, 10, 5033-5047. [CrossRef]

17. Abu-Hamdeh, N.H.; Bantan, R.A.R.; Alimoradi, A. Heat transfer optimization through new form of pin type of finned tube heat exchangers using the exergy and energy analysis. Int. J. Refrig. 2020, 117, 12-22. [CrossRef]

18. Guan, B.; Liu, X.; Zhang, T. Exergy analysis on optimal desiccant solution flow rate in heat exchanger for air dehumidification using liquid desiccant. Int. J. Refrig. 2021, 128, 129-138. [CrossRef]

19. Xie, J.H.; Cui, H.C.; Liu, Z.C.; Liu, W. Optimization design of helical micro fin tubes based on exergy destruction minimization principle. Appl. Therm. Eng. 2022, 200, 117640. [CrossRef]

20. Sundar, L.S.; Punnaiah, V.; Sharma, K.V.; Chamkhad, A.J.; Sousaa, A.C.M. Thermal entropy and exergy efficiency analyses of nanodiamond/water nanofluid flow in a plate heat exchanger. Diam. Relat. Mater. 2021, 120, 108648. [CrossRef]

21. Li, Z.; Sheikholeslami, M.; Jafaryar, M.; Shafee, A.; Chamkha, A.J. Investigation of nanofluid entropy generation in a heat exchanger with helical twisted tapes. J. Mol. Liq. 2018, 266, 797-805. [CrossRef]

22. Bahiraei, M.; Mazaheri, N. A comprehensive analysis for second law attributes of spiral heat exchanger operating with nanofluid using two-phase mixture model: Exergy destruction minimization attitude. Adv. Powder Technol. 2021, 32, 211-224. [CrossRef]

23. Saleh, B.; Sundar, L.S. Experimental study on heat transfer, friction factor, entropy and exergy efficiency analyses of a corrugated plate heat exchanger using Ni/water nanofluids. Int. J. Therm. Sci. 2021, 165, 106935. [CrossRef]

24. Bošnjaković, F. Nauka o Toplini, II Dio, 4th ed.; Tehnička knjiga: Zagreb, Croatia, 1976.

25. Galović, A. Termodinamika II, 7th ed.; FSB: Zagreb, Croatia, 2019.

26. Sekulić, D.P. Entropy generation in heat exchanger. Heat Transf. Eng. 1986, 2, 83-88. [CrossRef]

27. Bošnjaković, F. Nauka o Toplini, I Dio, 5th ed.; Tehnička Knjiga: Zagreb, Croatia, 1978.

28. Galović, A. Termodinamika I, 8th ed.; FSB: Zagreb, Croatia, 2021.

29. Shah, R.K.; Sekulić, D.P. Fundamentals of Heat Exchanger Design; John Wiley \& Sons: Hoboken, NJ, USA, 2003.

30. Cengel, Y.A. Heat Trasnfer, A Practical Approach, 2nd ed.; McGraw-Hill: Boston, MA, USA, 2003.

31. Roetzel, W.; Spang, B. C1 Thermal Design of Heat Exchangers. In VDI Heat Atlas, 2nd ed.; Stephen, P., Kabelac, S., Eds.; Springer: Berlin/Heidelberg, Germany, 2010; pp. 33-62. 